\title{
OPEN Retrieving zinc concentrations in topsoil with reflectance spectroscopy at Opencast Coal Mine sites
}

\author{
Bin Guo ${ }^{1,2 \bowtie}$, Bo Zhang ${ }^{1,2}$, Yi Su$^{1}$, Dingming Zhang ${ }^{1}$, Yan Wang ${ }^{1}$, Yi Bian ${ }^{1}$, Liang Suo ${ }^{1}$, \\ Xianan Guo ${ }^{1} \&$ Haorui Bai ${ }^{1}$
}

Heavy metals contaminations in mining areas aroused wide concerns globally. Efficient evaluation of its pollution status is a basis for further soil reclamation. Visible and near-infrared reflectance (VisNIR) spectroscopy has been diffusely used for retrieving heavy metals concentrations. However, the reliability and feasibility of calibrated models were still doubtful. The present study estimated zinc (Zn) concentrations via the random forest (RF) and partial least squares regression (PLSR) using ground in-situ Zn concentrations as well as soil spectral reflectance at an Opencast Coal Mine of Ordos, China in February 2020. The coefficient of determination $\left(R^{2}\right)$, root mean square error (RMSE), mean absolute error (MAE), and the ratio of performance to deviation (RPD) were selected to assess the robustness of the methods in estimating Zn contents. Moreover, the characteristic bands were chosen by Pearson correlation analysis and Boruta Algorithm. Finally, the comparison between RF and PLSR combined with eight spectral reflectance transformation methods was conducted for four concentration groups to determine the optimal model. The results indicated that: (1) Zn contents represented a skewed distribution (coefficient of variation $(\mathrm{CV})=33 \%$ ); $(2)$ the spectral reflectance tended to decrease with the increase of Zn contents during 580-1850 nm based on Savitzky-Golay smoothing (SG); (3) the continuous wavelet transform (CWT) demonstrated higher effectiveness than other spectral reflectance transformation methods in enhancing spectral responses, the $\mathrm{R}^{2}$ between $\mathrm{Zn}$ contents and the soil spectral reflectance achieved the highest $\left(R^{2}=0.71\right)$ by using CWT; $(4)$ the RF combined with CWT exhibited the best performance than other methods in the current study $\left(R^{2}=0.97, R P D=3.39\right.$, RMSE $=1.05 \mathrm{mg} \mathrm{kg}^{-1}, \mathrm{MAE}=0.79 \mathrm{mg} \mathrm{kg}^{-1}$ ). The current study supplied a scientific scheme and theoretical support for predicting heavy metals concentrations via the Vis-NIR spectral method in possible contaminated areas such as coal mines and metallic mineral deposit areas.

China is the world's largest coal producer and consumer, and coal provides more than 70 percent of total energy in China ${ }^{1}$. China has to confront the dilemma of balancing socio-economic development with environmental issues $^{2-7}$. Exploring mineral resources may lead to adverse effects on the ecological environment ${ }^{8,9}$. Abundant heavy metals residues in tailings of open-pit mines have been generated due to inefficient processing procedures of ore. What's more, severe soil heavy metals contaminations have been caused in nearby farmland and urban areas because of the abandoned mine tailings that are exposed to the surrounding soils and rarely reclaimed ${ }^{10-12}$. Ordos Municipality, in the Inner Mongolia Autonomous Region of northern China, has been undergoing extensive opencast coal exploitation during past decades. The area of coal mining increased from 7.12 to $355.95 \mathrm{~km}^{2}$, and the number of coal-mining increased from 82 to 651 during 1990-2015 in the Ordos ${ }^{13,14}$. It's reported that the $\mathrm{Zn}$ pollution in the topsoil of mining areas of Inner Mongolia and other places is relatively common ${ }^{15,16}$. Land productivity, ecological integrity, and habitat security were seriously threatened by heavy metals pollutions in mining areas ${ }^{16-20}$. Heavy metals are hazardous contaminants owing to their toxicity, persistency, easy uptake by plants, and long biological half-life ${ }^{21,22}$. Moreover, the heavy metals may cause stress on crops and hinder their growth, yield, and quality because the normal function of soil was destroyed by heavy metals ${ }^{23,24}$. Furthermore, human health is susceptible to heavy metals that may enter the body through biological chains ${ }^{25,26}$. If some heavy metals with both carcinogenic and teratogenic enter the bloodstream, they can dissolve red blood 
cells, destroy normal cells ${ }^{27}$. For example, Zn generates gastrointestinal distress including nausea, vomiting, and abdominal pain as well as irritation of the respiratory system ${ }^{28}$. Besides, cholesterol balance and fertility may be affected by $\mathrm{Zn}$ with long-term high dose exposure ${ }^{29}$. Lead $(\mathrm{Pb})$ can lead to dysfunction in the immune system, the reproductive system, and hematopoiesis. Moreover, the brain, kidney, liver, and nerves may be damaged by the accumulation of $\mathrm{Pb}^{30,31}$. Cadmium $(\mathrm{Cd})$ is one of the most toxicant hazardous materials, which can be absorbed by vegetables owing to its lipid. It can generate serious negative effects on public health with a level of $>0.2 \mathrm{mg} \cdot \mathrm{kg}^{-1}$ in leafy vegetables. Additionally, Cd also blocks plant growth and photosynthesis of pigments ${ }^{21}$. Intaking of Nickel (Ni) may negatively impact public health owing to its accumulation. Previous studies have demonstrated an increased incidence of cancers to be related to chronic exposure to $\mathrm{Ni}^{32}$. Consequently, it is urgent to explore the distribution and evaluate the pollution level of heavy metals especially toxic materials such as $\mathrm{Zn}, \mathrm{Cd}$, and $\mathrm{Pb}$ in surface coal-mining areas ${ }^{33,34}$.

In-situ sampling and laboratory analysis are common methods with high accuracy for obtaining soil heavy metals contents ${ }^{35}$. The instruments including atomic absorption spectroscopy ${ }^{36}$, atomic fluorescence spectrometry $^{37}$, spectrophotometry ${ }^{38}$, and other analytical methods based on optical instruments are always used to measure heavy metals concentrations. However, the above methods are time-consuming and costly ${ }^{39,40}$. Besides, it is inefficient to use the above methods to detect the spatiotemporal dynamic distribution of soil heavy metals on a large scale ${ }^{41,42}$. Alternatively, Vis-NIR spectroscopy with multiple bands (350-2500 nm), strong spectral continuity, and wide coverage, provides a new perspective for monitoring environmental issues over large scales ${ }^{43}$. Thus far, Vis-NIR spectroscopy has been widely utilized in different fields including predicting soil organic carbon ${ }^{44}$ and detecting heavy metals in agricultural soils, suburban soils, and river sediments ${ }^{41,45,46}$. Additionally, the mining areas accompany with complex topography increased the difficulty of exploring heavy metals distribution using traditional methods, which urged an alternative method for detecting hazardous materials in mining areas. The Vis-NIR spectroscopy supplied a new perspective to investigate heavy metals pollution. Currently, the accuracy of the calibration model for soil heavy metals concentration based on Vis-NIR spectroscopy is affected by many factors. Also, previous studies reported that spectral response information was hard to be extracted and stripped from weak soil spectral signals. The preprocessing of spectral reflectance can effectively promote the accuracy and robustness of the calibration model for heavy metals contents ${ }^{47-49}$. However, unsuitable preprocessing methods may lose the specific spectral information of toxic materials. CWT has been used to extract spectral detail information and proved it can effectively improve the prediction capacity of heavy metals concentrations using the Vis-NIR spectral inversion model ${ }^{50}$.

Moreover, the suitable calibration model using the Vis-NIR spectral method for heavy metals contents is very helpful. Published studies on Vis-NIR spectral inversion models for heavy metals concentrations can be divided into two classes including statistical analysis models and machine learning models ${ }^{51,52}$. Statistical analysis models including multiple linear regression (MLR), multiple linear stepwise regression (MLSR), principal component regression (PCR), and PLSR are widely used for determining heavy metals contents ${ }^{53-55}$. However, some issues such as the autocorrelation and multicollinearity of samples have been neglected when using linear regression to construct the models. Machine learning algorithms such as RF overcome the above problems, which linear or non-linear relationships between dependent and independent variables can be detected through the random forest $^{56-58}$. Whereas, the related researches concerning the application of combining CWT with RF for estimating heavy metals concentrations in topsoil from coal-mining areas were still rarely reported. Thus, it is indispensable to compare the effects of different pretreatments on the calibration model and evaluate the efficiency of the spectral reflectance preprocessing techniques for determining the optimal preprocessing method in heavy metals concentration modeling. Meanwhile, the determination models of soil heavy metals concentrations were often performed using spectral variables from Vis-NIR spectral data collected from soil samples in the laboratory. However, spectra obtained in the laboratory and the field were completely diverse due to some uncertainties and disturbances including the preprocessing of samples, such as air-drying, grinding, and controlling the spectral measurement conditions in the laboratory. Soil spectra surveyed in the field were influenced by many factors such as soil particle size, soil surface conditions, soil water content, solar radiation, soil organic matter, temperature, and ambient light ${ }^{21}$. Therefore, it is still a big challenge to take advantage of the lab-derived models based on Vis-NIR spectroscopy to infer concentrations of heavy metals in soil. In general, the necessity of the current study was to evaluate the feasibility and reliability of using the Vis-NIR spectroscopy in estimating heavy metals contents at an open-pit coal mine, to compare the effect of various spectral transformation methods on the accuracy of the estimation models, and to determine if the concentrations of soil samples generate effects on the accuracy in retrieving heavy metals contents or not.

The objectives of this study are to (1) measure $\mathrm{Zn}$ concentrations, and survey in-situ reflectance spectra, lab-based processed reflectance spectra, and lab-based unprocessed reflectance spectra of soil samples from an Opencast Coal Mine of Ordos, China; (2) select optimal characteristic bands based on Pearson correlation coefficient as well as the Boruta algorithm; (3) calibrate $\mathrm{Zn}$ concentrations using statistical analysis and random forest based on $\mathrm{Zn}$ contents and spectral reflectance data; (4) evaluate the performance of related models including PLSR and RF combined with different spectral reflectance transformation methods, then determining the optimal prediction method for Zn contents.

\section{Materials and methods}

Study area. The Ordos city, with an area of approximate $86,000 \mathrm{~km}^{2}$ and within $37^{\circ} 35^{\prime} \sim 40^{\circ} 51^{\prime} \mathrm{N}$ and $106^{\circ} 42^{\prime} \sim 111^{\circ} 270^{\prime} \mathrm{E}$, is located in the Inner Mongolia Autonomous Region of north China. The topography with an elevation between 850 and $2149 \mathrm{~m}$ is high in the west and low in the east ${ }^{59}$. The Ordos city with a temperate continental climate has an annual sunshine duration between 2716.4 and $3193.9 \mathrm{~h}$, an average annual temperature between 5.3 and $8.7^{\circ} \mathrm{C}$, and mean annual precipitation ranging from 170 to $450 \mathrm{~mm}^{14}$. The Ordos 


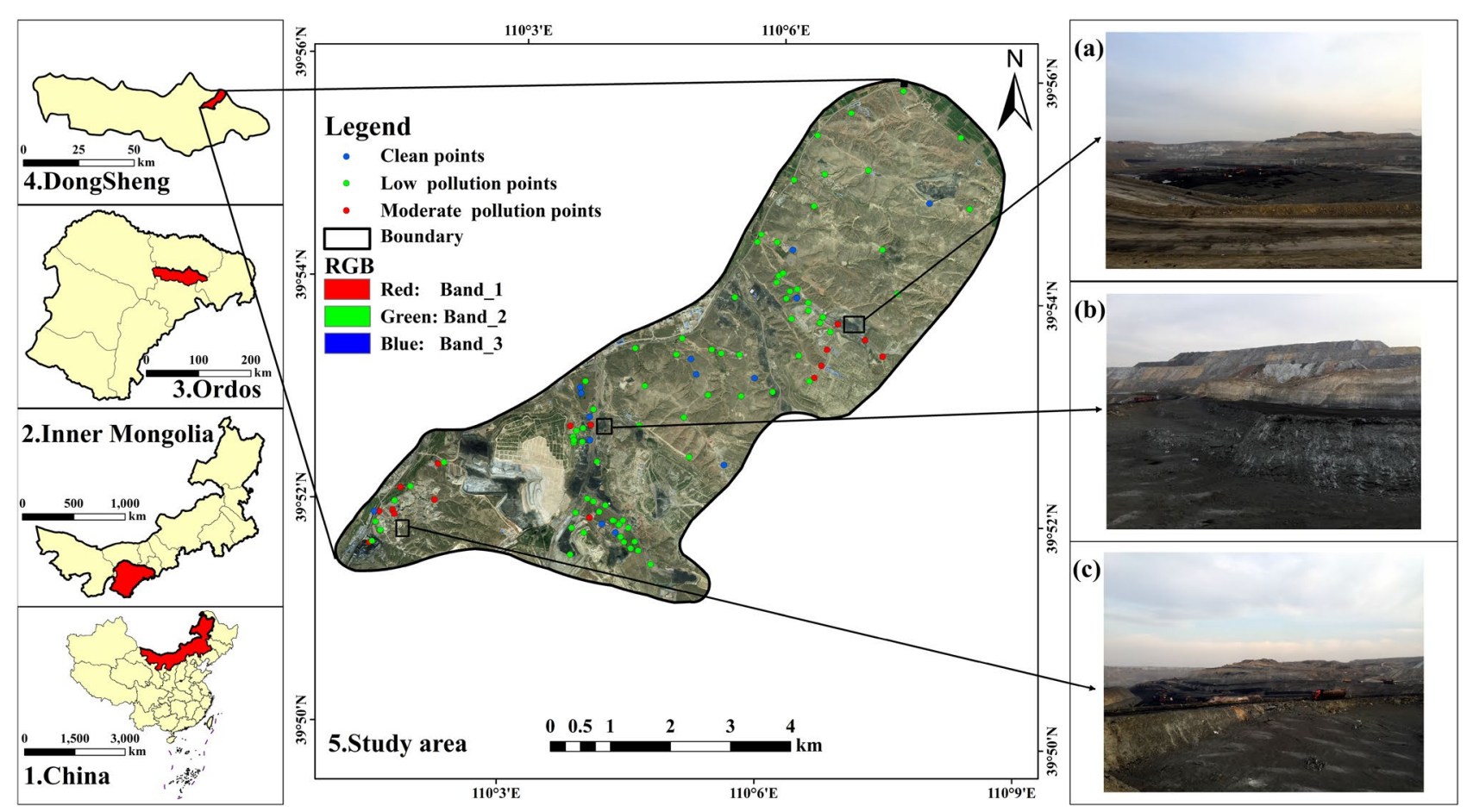

Figure 1. The geographical location of the study area and spatial distribution of the in-situ sampling sites are classified by pollution level. (a), (b), and (c) represent the actual conditions of the study area. (Note: soil samples were classified into three types based on the background value $(B V)^{15}$ of the Inner Mongolia Autonomous Region using the contamination factor method ${ }^{61,62}$, including clean $\left(\mathrm{Zn} \leq 48.6 \mathrm{mg} \mathrm{kg}^{-1}\right)$, low pollution $\left(48.6 \leq \mathrm{Zn} \leq 97.2 \mathrm{mg} \mathrm{kg}^{-1}\right)$, and moderate pollution $\left(97.2 \leq \mathrm{Zn} \leq 145.8 \mathrm{mg} \mathrm{kg}^{-1}\right)$, respectively. The Fig. 1 was generated by ArCGIS 10.0 that was obtained from https://www.esri.com/en-us/arcgis/products/arcgis-deskt op/, and the satelite image used in Fig. 1 (sub Fig. 5) was downloaded from Google Earth (https://earth.google. $\operatorname{com} /))$.

has abundant coal resources. The coal-bearing area covers about $70 \%$ of the total area and the proven coal reserves account for 201.75 trillion tons. Specifically, the Ordos can be divided into four coalfields including the Zhungeer in the east, the Zhuozishan in the west, the Dongsheng in the south, and the Wulangeer in the north, respectively. Also, the Ordos has various types of coal, such as brown coal, cannel coal, and no-caking coal. Most of those coal resources are buried in a shallow layer that is suitable for opencast mining. Coal production in the Ordos increased from 6.11 million tons to 678.93 million tons from 1990 to 2019 . The coal industries played an important role in the socio-economic development of Ordos. However, recently, the environment is deteriorating because of mining activities especially the seriously polluted soil (bare soil) near the mining areas. So, the present study chose the Dongsheng coalfield with an area of approximately $63.2 \mathrm{~km}^{2}$ as the sampling area ${ }^{60}$. The location of the study area and the distribution of the in-situ sampling sites are shown in Fig. 1.

Workflow. The workflow of the current study was described as follows (Fig. 2): (1) Collecting three sorts of soil spectral reflectance including in-situ, lab-based processed, lab-based unprocessed, respectively, and the $\mathrm{Zn}$ concentrations were measured by an XRF instrument. A logarithmic transformation method was implemented to modify the skewed distribution of $\mathrm{Zn}$ concentration. Furthermore, soil samples were classified into three types based on the BV of the Inner Mongolia Autonomous Region using the contamination factor method, including clean $\left(\mathrm{Zn} \leq 48.6 \mathrm{mg} \mathrm{kg}^{-1}\right)$, low pollution $\left(48.6 \leq \mathrm{Zn} \leq 97.2 \mathrm{mg} \mathrm{kg}^{-1}\right)$, and moderate pollution ( $\left.97.2 \leq \mathrm{Zn} \leq 145.8 \mathrm{mg} \mathrm{kg}^{-1}\right)$, respectively. (2) Eight preprocessing methods in terms of continuum removal (CR), the first derivative of reflectance (FD), the second derivative of reflectance (SD), Savitzky-Golay smoothing (SG), absorbance transformation (ABS), Multiplicative Scatter Correction (MSC), Standard Normal Variate (SNV), and CWT were introduced to deduct spectral outliers and promote spectral response features of $\mathrm{Zn}$ after removing noisy regions (The detailed description of noisy regions can be found in "The spectral characteristics of soil samples under three conditions including in-situ, the lab-based processed, and the lab-based unprocessed"). (3) The integration of the Boruta algorithm and the Pearson correlation coefficients was adopted to choose the significantly important spectral variables for estimating Zn concentration. (4) The entire samples were separated into calibration sets and validation sets according to the 2:1 ratio. (5) PLSR and RF have been fitted to calibrate $\mathrm{Zn}$ concentration using the in-situ $\mathrm{Zn}$ concentrations dataset and the spectral reflectance of $\mathrm{Zn}$, and the performance was compared based on specific indicators concerning $\mathrm{R}^{2}$, RMSE, MAE, and RPD.

Sampling and measuring. The sampling route was designed according to FOREGS Geochemical Mapping Field Manual ${ }^{63}$ concerning agricultural production, industrial distribution, waste discharge, road and river 


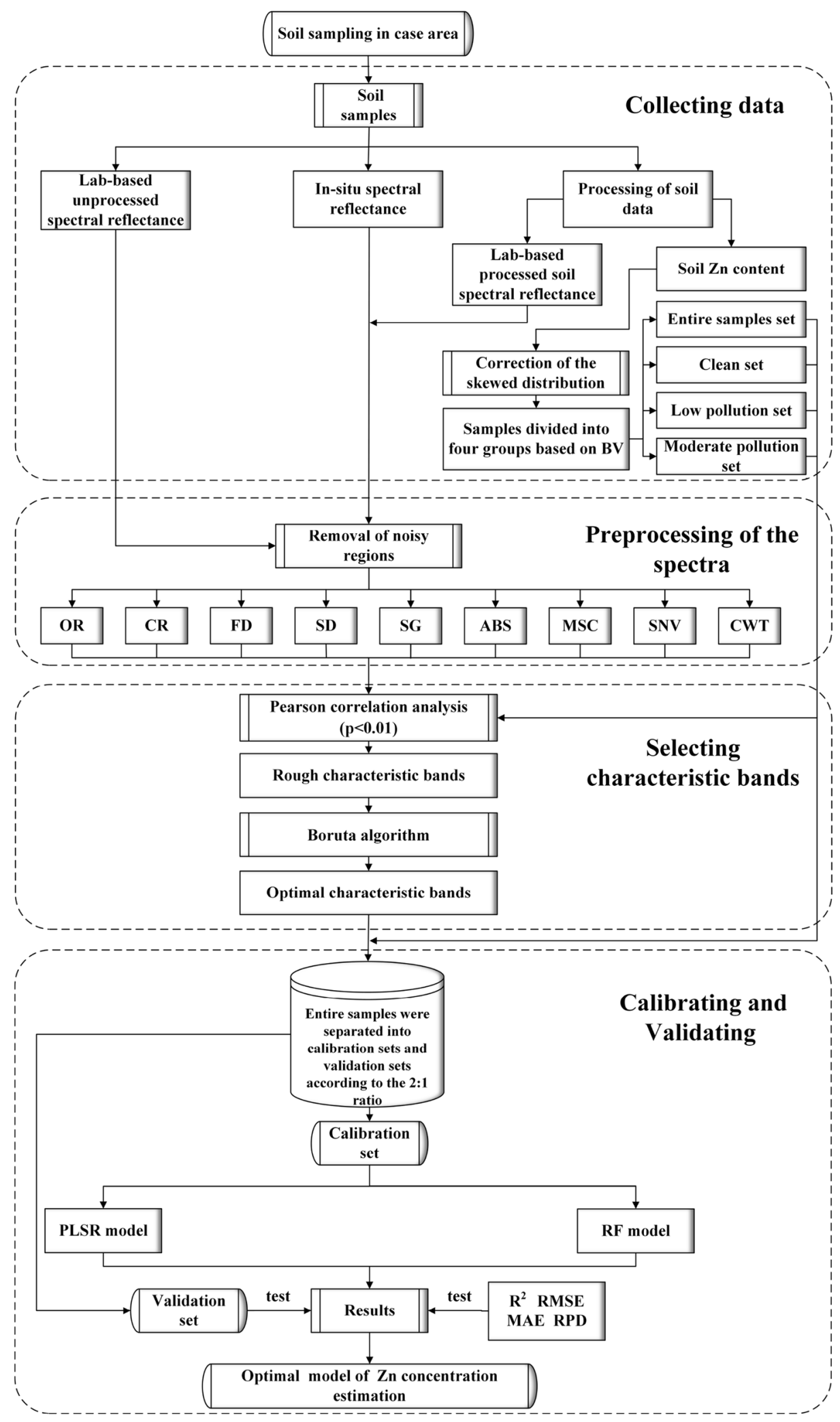

Figure 2. The workflow of this study. (Note: OR represents the original spectral reflectance of $\mathrm{Zn}$ ). 
networks, and soil type. A total of 111 in-situ soil samples $(0-20 \mathrm{~cm})$ were collected using a stainless-steel trowel in the study area on February 20, 2020. A portable Global Navigation Satellite System (GNSS) device was used to determine the World Geodetic System 1984 (WGS-84) coordinate of each sample site (Fig. 1) ${ }^{64}$. Each sample consisting of five subsamples with a wintersweet shape that were randomly collected from the surroundings, pooled, homogenized, and then reduced to a weight of $400 \mathrm{~g}$ to form a representative sample ${ }^{23}$. Additionally, samples were packaged back to the lab with plastic bags. In the lab, first, the samples were wind-dried. Then, soil samples were squashed with a glass stick and avoided impurities, crushed stone, and other alien elements. Next, an electric thermostatic air drying oven (DGG-9053AD, Shanghai, China) was utilized to exsiccate soil samples until constant weight. Next, all samples were sieved using a $0.7 \mathrm{~mm}$ polyethylene sieve and transferred into new plastic bags. Then each soil sample with $4 \mathrm{~g}$ weight was put into a $32 \mathrm{~mm}$ mold and squeezed a tablet with a boric acid edge under 30-ton pressure for X-ray fluorescence (SPECTRO xSORT, SPECTRO Analytical Instruments $\mathrm{GmbH}$, Boschstr. 10, 47533 Kleve, Germany) analysis ${ }^{65,66}$. The mean content of every sample was determined by repeating three-time measurements for decreasing errors. Finally, specific software for X-ray fluorescence (SPECTRO xSORT) named Sample Result Manager was used to pretreat heavy metals concentrations data. The eight heavy metals concentrations including $\mathrm{Zn}, \mathrm{Cd}, \mathrm{As}, \mathrm{Co}, \mathrm{Cu}, \mathrm{Ni}, \mathrm{Pb}$, and Mn were obtained. The GSD-series and GSS-series reference samples (Institute of Geophysical and Geochemical Prospecting, Lang fang, China) have been introduced to calibrate the SPECTRO xSORT, and the results demonstrated that the SPECTRO XSORT was reliable with a relative standard deviation ranged from 3 to $5 \%$.

Spectral measurements and preprocessing. The reflectance spectra of the soil samples were surveyed by a FieldSpec 4 portable object spectrometer manufactured by ASD (Analytica Spectra Devices., Inc, USA) that covers 350-2500 $\mathrm{nm}$ spectral range with $1 \mathrm{~nm}$ spectral resolution. The reflectance spectral of three different types of samples including in-situ, lab-based processed, and lab-based unprocessed, respectively.

Under field conditions, the impurity such as stones, roots, leaves were excluded before sampling for assuring the purity of the soil samples. The soil spectra were measured using an ASD spectrometer at each position of five subsamples, and the mean spectrum of the five subsamples was chosen as the spectrum of the specific soil sample. To avoid the shadow when scanning the soil samples, firstly, making sure the probe was vertical to the ground. Secondly, adjusting the position to avoid the shadow to cover the soil samples, and to ensure the soil samples were completely exposed to the sun. Besides, a whiteboard with $99 \%$ reflectance was utilized to calibrate the spectrometer before measuring at each in-situ sampling site. Meanwhile, a warm-up with 30 min duration was carried out for the spectroradiometer to minimize errors. Additionally, 3-time spectral surveys were implemented, and calculated the mean value for each sampling site as the representative spectrum to decrease errors. All spectra were measured from 10 am to $2 \mathrm{pm}$ under clear weather conditions because the sun was the only source of illumination at that condition. The fiber optic probe was put at approximately $15 \mathrm{~cm}$ above the soil samples vertically and in the opposite direction with solar radiation.

Accordingly, two kinds of samples concerning lab-based processed, and lab-based unprocessed reflectance spectra were surveyed under lab conditions using the same spectrometer. All spectral measurements were conducted in a dark room and all surveyors were required to dress in black clothes without any reflection to avoid unnecessary spectral noise. A $1000 \mathrm{~W}$ halogen lamp was used as the simulation light source. The field observation angle between the vertical direction and the light was set as $15^{\circ}$. The size of the soil samples container for spectra scanning is $10 \mathrm{~cm} \times 10 \mathrm{~cm}$. The field of view (FOV) is $25^{\circ}$, and the diameter of the field of view is $7 \mathrm{~cm}$. Clearly, the surface area of the soil sample container completely covered the area of soil spectra. So, the size of the soil container can assure the purity of the soil samples spectra. The distance between the halogen lamp and the soil samples was $30 \mathrm{~cm}$. Moreover, the distance and angle between the probe and the soil samples were $15 \mathrm{~cm}$ and $90^{\circ}$, respectively. The same whiteboard was also utilized to calibrate the spectroradiometer before measuring. Similar to the field spectral measurement, before starting the measurement, a warm-up of 30 min duration for the spectroradiometer was also implemented. Every sample was put into a black petri dish of a specific size. The size of the black petri dish for spectra scanning is $10 \mathrm{~cm} \times 10 \mathrm{~cm}$. The field of view (FOV) is $25^{\circ}$, and the diameter of the field of view is $7 \mathrm{~cm}$. Clearly, the area of the soil sample container completely covered the area of soil spectra. The survey was conducted 3-time for reducing errors.

The process of collecting spectral reflectance was influenced by many potential factors such as survey device, soil sample, and lab conditions. The spectra may be worsened due to the above factors. So, the methods of transform spectral reflectance were always introduced to reduce the spectral noise. The Continuum Wavelet Transform (CWT) was selected to solve the above issue. Meanwhile, seven spectral transform methods including continuum removal (CR), the first derivative of reflectance (FD), the second derivative of reflectance (SD), Savitzky-Golay smoothing (SG), absorbance transformation (ABS), Multiplicative Scatter Correction (MSC), and Standard Normal Variate (SNV) were also implemented for comparison with the CWT. Twenty-one points and a quadratic polynomial were adopted to reduce spectral noise through the SG smoothing process.

Wavelet transform consists of two sorts concerning CWT and Discrete Wavelet Transform (DWT). The CWT was selected as a spectral transform method in this study. Spectral reflectance was decomposed into wavelet coefficients using different scales in terms of $2,2^{2}, 2^{3}, 2^{4}, 2^{5}, 2^{6}, 2^{7}, 2^{8}, 2^{9}, 2^{10}\left(\mathrm{~L}_{1}-\mathrm{L}_{10}\right)$ based on Gaussian 4 function served as the mother wavelet ${ }^{50}$. The Gaussian 4 was adopted as the mother wavelet function for soil spectral absorption features was close to the Gaussian function ${ }^{67}$. The basic function of the Wavelet Transform was as follows.

If $\psi(t) \in L^{2}(R)$ is a square-integrable function of its Fourier transform, it then satisfies the following expression: 


$$
C_{\psi}=\int_{R} \frac{\left|\psi^{\Lambda}(\omega)\right|^{2}}{(\omega)} \mathrm{d} \omega<\infty
$$

where $\psi(t)$ denotes the wavelet basis function.

The wavelet basis function can be scaled and assessed to obtain the wavelet basis function, $\psi_{\alpha, \tau}(t)$, as follows:

$$
\psi_{\alpha, \tau}(t)=\frac{1}{\sqrt{\alpha}} \psi\left(\frac{t-\tau}{a}\right) \alpha, \quad \tau \in R ; \alpha>0
$$

where $a$ denotes the scale factor, $\tau$ denotes the translation factor, and $t$ denotes the spectral bands. One-dimensional spectra were transformed into a two-dimensional $\mathrm{m} \times \mathrm{n}$ matrix by CWT. Each row of the matrix denotes a wavelet coefficient at a different decomposed scale.

Spectral feature selection and correction of skewed data. Spectral feature selection. The Boruta algorithm ${ }^{68,69}$ designed as a wrapper around a Random Forest classification was introduced to conduct the spectral feature selection because it can provide an intrinsic measure of the importance of each variable, called the $\mathrm{Z}$-score. The Z-score of the original variables and the expected Z-score from the randomly selected features generated by random permutation were compared to determine the terminal variables with a larger Z-score than that of all the randomly selected features. In this study, the integration of the Boruta algorithm and the Pearson correlation coefficients with a significance level of 0.01 was used to select the significantly important spectral variables for estimation of the $\mathrm{Zn}$ concentration ${ }^{70}$.

Correction of skewed data. Logarithmic transformations are widely used to adjust a highly skewed variable into a more approximately normal variable due to their effectiveness and convenience ${ }^{64}$. Besides, logarithmic transformations are always used in conditions where the independent and dependent variables exhibit a nonlinear relationship and still preserve the linear regression model. Specifically, soil samples generally represent lognormal distributions ${ }^{71}$. So, the natural logarithm transformation was selected to correct the skewed distributions of the heavy metals concentration in the current study.

Calibration and validation. Partial least squares regression (PLSR). PLSR proposed by Herman O. A. Wold is a spectral analysis method that includes multiple linear regression, canonical correlation analysis, and principal factor analysis ${ }^{72}$. PLSR is suitable for Vis-NIR spectral bands with collinearity and spectral noise ${ }^{73}$. PLSR projects a group of spectral and dependent response variables into a low-dimensional space, thereby decreasing dimensionality and excluding noise. Recently, PLSR has been widely used in soil heavy metals concentrations retrieving based on Vis-NIR spectral technology ${ }^{74}$. Leave-one-out cross-validation was introduced to obtain the number of latent variables (LVs) of PLSR. The maximum number of LVs was chosen to control the number of LVs to eliminate over-fitting. The number of LVs with the lowest root mean square error of crossvalidation (RMSECV) was adopted in the calibration ${ }^{37}$.

Random forest $(R F)$. The RF algorithm ${ }^{75}$ is a bagging method based on regression tree (CART) analysis and classification $^{76}$. The advantages of RF are the significance of each feature can be assessed with unbiased estimation during the classification process, and the issues with numerous missing data can be solved. Additionally, the efficiency of the RF model in processing big data without any dimensionality reduction outperforms traditional models $s^{77}$. The classification trees are used to decide on choosing the optimal tree in predicting. The number of classification trees in RF is large, and all variables have to be inputted into each tree with an independent feature for classing. Moreover, $99.9 \%$ of unrelated trees conduct predictions that cover all conditions. The basic theory of RF bagging is to choose the results of several weak classifiers and form a strong classifier. The processes for generating classification trees and mathematical equations of the RF model can be found in related literature, the current study did not state corresponding contents again due to limited space ${ }^{78,79}$. Three parameters including the number of trees of the classification tree (ntree), the variable selection number (mtry) when branching, and the size of leaf (node size) were important for constructing an RF model. The default parameters for the node size were adopted to construct each model ${ }^{67}$. Several parameters were tested for determining the optimal value of mtry and ntree of the RF model. So, the optimization of mtry ranged from 1 to 100 at the interval of 1 , and the best ntree varied from 1 to $\mathrm{P}-1$ at the interval of 1 . P represents independent variables.

Validation. Before the calibrating, the samples needed to be grouped. The entire samples were separated into calibration sets and validation sets according to the 2:1 ratio. The concentrations of heavy metals were ranked from the lowest to the highest for selecting three adjacent samples as a group. For each group, two samples were chosen randomly as the calibration set, and the remained one was selected as the validation set ${ }^{80}$. The calibration set was used to fit the model, and the validation set was utilized to assess the performance of the model.

Four indicators including coefficient of determination $\left(\mathrm{R}^{2}\right)$, root mean squared error of prediction (RMSE), mean absolute error (MAE), and the ratio of performance to deviation (RPD) was chosen for evaluating the accuracy and robustness of the models. The detailed information concerning the four accuracy indicators was not described due to the limited space, and the related statements can be found in previous studies ${ }^{81-84}$.

Software. Spectral pretreatments and the Boruta algorithm were executed via R version 3.6.3. Moreover, the PLSR and RF models were run in MATLAB version 2016b. Finally, Sample Result Manager (a specific software for SPECTRO xSORT), and ArcGIS10.0 were used for analyzing and mapping in this paper. 


\begin{tabular}{|l|l|l|l|l|l|l|l|l|l|l|l|}
\hline Element & Maximum & Minimum & Mean & Range & Median & SD $^{\mathbf{a}}$ & $\mathbf{C V}^{\mathbf{b}}$ & Skewness & Kurtosis & BV $^{\mathbf{c}}$ & PR $^{\mathbf{d}}$ \\
\hline $\mathrm{Zn}$ & 157.00 & 30.05 & 67.98 & 126.95 & 61.30 & 22.48 & 33 & 1.29 & 1.68 & 48.6 & 87.39 \\
\hline
\end{tabular}

Table 1. Statistics of the collected soil samples for $\mathrm{Zn}$ concentration $\left(\mathrm{mg} \mathrm{kg}^{-1}\right) .{ }^{\mathrm{a}} \mathrm{SD}$ : standard deviation, ${ }^{\mathrm{b}} \mathrm{CV}$ : coefficient of variation in \%. ${ }^{\mathrm{c}} \mathrm{BV}$ : the soil $\mathrm{Zn}$ concentration background value of Inner Mongolia Autonomous Region ${ }^{15}$. ${ }^{\mathrm{P}} \mathrm{PR}$ : the percentage of contaminated samples (Threshold $=48.6 \mathrm{mg} \mathrm{kg}^{-1}$ ).

\begin{abstract}
Results
Descriptive statistic. Table 1 and Fig. 3a revealed the statistical features of the $\mathrm{Zn}$ element. The concentration of $\mathrm{Zn}$ ranged from 30.05 to $157.00 \mathrm{mg} \mathrm{kg}^{-1}$. Although the mean concentration of $\mathrm{Zn}\left(67.98 \mathrm{mg} \mathrm{kg}^{-1}\right)$ did not surpass the background values of the Chinese Environment Quality Standard for Soils released by the Ministry of Environmental Protection of China in 2018 (200 mg kg-1) (GB15618-2018), it exceeded the background value of the Inner Mongolia Autonomous Region $\left(48.6 \mathrm{mg} \mathrm{kg}^{-1}\right)^{15}$. Moreover, more than $87 \%$ of the soil samples were polluted by the $\mathrm{Zn}$ element, $73 \%$ and $14 \%$ account for minor pollution as well as moderate pollution (Fig. 1). The outcome demonstrated that plenty of $\mathrm{Zn}$ deposited in the topsoil of the study area. Also, the SD $\left(22.48 \mathrm{mg} \mathrm{kg}^{-1}\right)$ of $\mathrm{Zn}$ concentration was relatively high because some samples exhibited extremely higher concentrations (157, 135 , and $128 \mathrm{mg} \mathrm{kg}^{-1}$ ) than the neighbors. Additionally, the variation of the measured $\mathrm{Zn}$ concentration demonstrated significant spatial heterogeneity based on the range ( 30.05 to $\left.157.00 \mathrm{mg} \mathrm{kg}^{-1}\right)$, SD $\left(22.48 \mathrm{mg} \mathrm{kg}^{-1}\right)$, and $\mathrm{CV}(33 \%)$ for $\mathrm{Zn}$. We can infer that the concentration of $\mathrm{Zn}$ in the topsoil of the study area was largely affected by long-term anthropic activities especially mining activities. The Tablel showed that Zn represented a skewness distribution (Skewness $=1.29$ ) with heavy tails (Kurtosis $=1.68$ ). The skewed and irregular distribution may generate negative effects on retrieving soil metals contents with Vis-NIR spectroscopy ${ }^{64,85}$. Therefore, a natural logarithm transformation was selected to correct the negatively skewed distribution (Fig. 3b).
\end{abstract}

The spectral characteristics of soil samples under three conditions including in-situ, the lab-based processed, and the lab-based unprocessed. The in-situ soil spectra from the mining area were shown in Fig. S1e. The lab-based processed spectra and the lab-based unprocessed spectra from the mining area were illustrated in Fig. S1a,c), respectively. Clearly, though the spectral reflectance of each soil sample changed according to the wavelength, the varied trend of spectral reflectance for all soil samples was similar. The spectral curves with smoothed features represented an upward trend, and the spectral reflectance values were ranged from 0 to 0.6 (Fig. S1a). Specifically, the curves were separated into three wavelength bands. Although spectral reflectance was low, the values increased rapidly during the visible light band (400-780 nm). The spectral reflectance was relatively stable and high at the short-wave near-infrared waveband $(780-2100 \mathrm{~nm})$. The spectral reflectance decreased slowly during the long-wave near-infrared waveband (2100-2500 nm). Clearly, atmospheric water vapor exhibited strong absorptive effects on spectra especially around 1400 and $1900 \mathrm{~nm}$ and above $2400 \mathrm{~nm}$ during field spectral measurement ${ }^{86}$. So, the spectral noise aroused by atmospheric water vapor has been removed from the raw spectra (Fig. S1e,f), and the spectra mainly distributed during 350-399 and 2400-2500 nm defined as noisy regions where reflectance spectra exhibited unstable features and were always excluded in published studies has been removed (Fig. S1b,d) ${ }^{87}$. Another obvious fluctuation of the curves around $1000 \mathrm{~nm}$ was detected probably due to the interference of iron oxide ${ }^{88}$. A strong absorptive belt of the spectral curves was found at the near-infrared region. Specifically, water led to the obvious absorption at $1400 \mathrm{~nm}$ and $1900 \mathrm{~nm}$, and the crystal lattice water at $1450 \mathrm{~nm}$ and $2200 \mathrm{~nm}$ also presented significantly absorptive capabilities (Fig. S1b,d) ${ }^{37}$. The spectral reflectance increased sharply from $400 \mathrm{~nm}$ due to the presence of organic matter and iron ions ${ }^{89}$. Meanwhile, one small valley occurred at approximately $2200 \mathrm{~nm}$ owing to metals hydroxyl stretching ${ }^{45,90}$. Obviously, the spectral reflectance obtained from the field was relatively lower than collected from the laboratory because the soil water exhibits an absorption effect on spectral reflectance (Fig. S1a,e).

The mean CR, FD, SD, SG, ABS, MSC, SNV, and CWT spectral reflectance curves under lab-based processed are illustrated in Fig. S2. The same methods were implemented for the other two situations including lab-based unprocessed and in-situ, and the results were presented in Figs. S3 and S4. Clearly, the reflectance spectra of soil were decreased with the concentration increased during the wavelengths 580-850 nm (Fig. S2SG, MSC). The reflectance spectra showed similar spectral shapes but with variable spectral intensities because the color of the soil sample gradually darkened may be affected by the increase in the heavy metals content, and the reflectance absorbed additional light energy, such that the spectral curve slowly decreased ${ }^{91}$. CWT could hardly extract obvious spectral response at the $\mathrm{L}_{1}-\mathrm{L}_{3}$ scales (Fig. $\mathrm{S}_{2} \mathrm{~L}_{1}-\mathrm{L}_{3}$ ). On the contrary, the relatively significant spectral response with sharp absorption peaks could be retrieved in the condition of increasing of decomposition scales (Fig. $\mathrm{S}_{2} \mathrm{~L}_{4}-\mathrm{L}_{6}$ ). Meanwhile, the spectral strength gradually was enhanced with the CWT scales increasing (Fig. $\mathrm{S}_{2} \mathrm{~L}_{1}-\mathrm{L}_{10}$ ). FD, SD, ABS, SG, MSC, and CR revealed a relatively weak capacity in increasing the responses for reflectance spectra compared with CWT in a particular wavelength. The original spectral reflectance curve generated by absorption was relatively less pronounced with broad and smooth features. The absorption peaks appeared at approximately 1400,1900 , and $2200 \mathrm{~nm}$. So, the spectral reflectance transformation methods were conducted to enhance the original spectral reflectance response. The characteristics of the original spectral reflectance have been increased. Absorption peaks were observed at approximately 500, 950, 1350, 1900, and $2200 \mathrm{~nm}$ using CR, 550, 1000, 1325, 1350, 1375, 1800, 1875, 2200, and $2250 \mathrm{~nm}$ via FD, and 1000, 1375, $1800 \mathrm{~nm}$ through SD. The baseline drifts and mixed overlapping peaks were efficiently deducted by FD and SD because the spectral reflectance became gradually approximately 0 . 

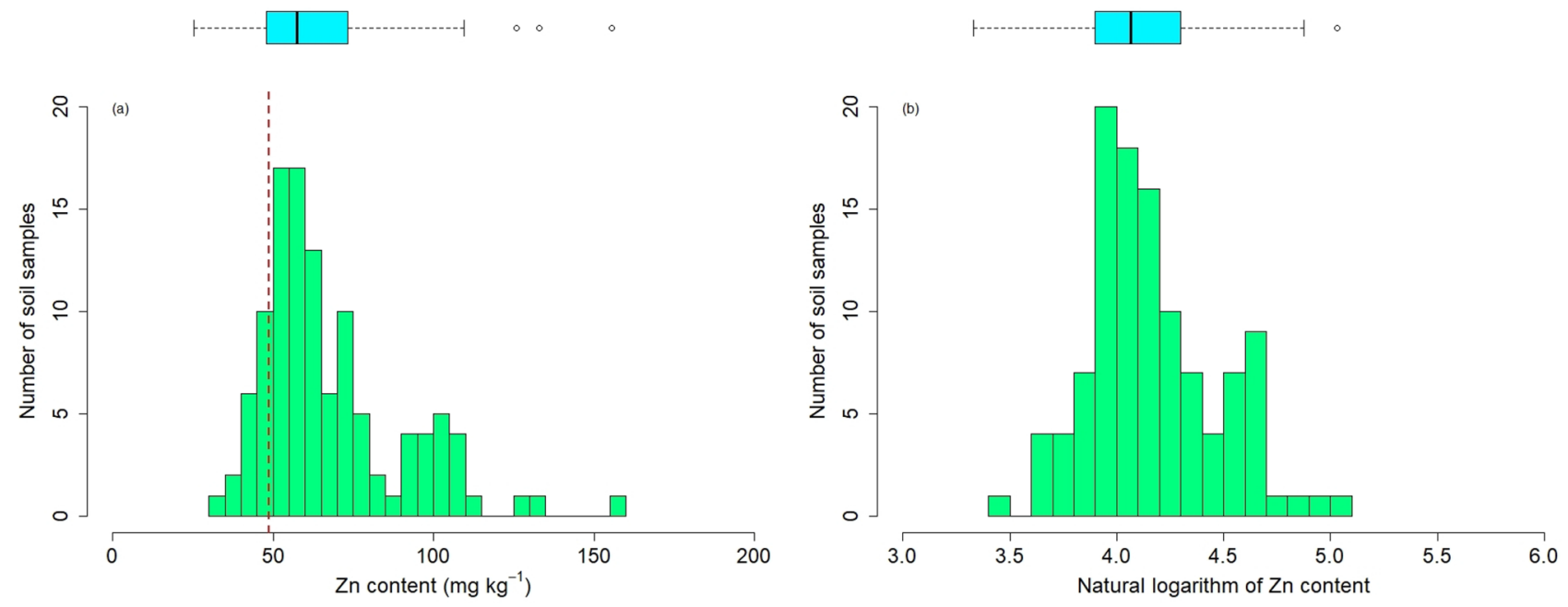

Figure 3. Histogram and box plot of $\mathrm{Zn}$ concentration of the topsoil in the study area (No. of samples $=111$ ). (Note: Rad dashed curve is the soil $\mathrm{Zn}$ concentration background value of Inner Mongolia Autonomous Region, dashed circle denotes the outliers of soil $\mathrm{Zn}$ concentration).

Selecting the characteristic bands based on Pearson correlation coefficients and the Boruta algorithm. First, the Pearson correlation coefficients were implemented to analyze the relations of $\mathrm{Zn}$ concentration for the three groups corrected by the natural logarithmic transformation method with soil spectral reflectance transformed by eight methods including CR, FD, SD, SG, ABS, MSC, SNV, and CWT. The rough characteristic bands were determined by the correlation coefficients square $(\mathrm{R}>0.6)^{50,92}$. Second, The Boruta algorithm was carried out to choose the optimum characteristic bands based on the Z-score using the rough characteristic bands.

Figure 4 revealed that all of the $\mathrm{R}^{2}$ for the original spectrum was less than 0.1 and below the red dashed line $\left(R^{2}=0.36\right)$. The $R^{2}$ of the spectrum after transforming was notably larger than the original spectrum that represented the spectral reflectance transformation methods could increase the sensitivity of reflectance response sheltered in the soil spectral reflectance data compared to the original spectral variables. The peak positions for $\mathrm{R}^{2}$ varied according to the spectral transformation methods and spectral wavelength. For the two conditions without any sample processing in terms of lab-based unprocessed and in-situ, no matter what spectral reflectance transformation methods we chose no obvious rough characteristic bands were existing. On the contrary, the rough characteristic bands were mainly concentrated during about 1347-1354 nm, 1699-1867 nm, 2041- $2096 \mathrm{~nm}$, 2132-2174 nm, 2196-2210 nm, 2218-2251 nm, 2330-2347 nm for lab-based processed. Meanwhile, three transformation methods including CR, FD, and SNV exhibited higher sensitivity than other methods for detecting rough characteristic bands. The maximum $\mathrm{R}^{2}=0.56$ was found at $2142 \mathrm{~nm}$ with $\mathrm{CR}$, followed by $1349 \mathrm{~nm}$ with an $\mathrm{R}^{2}=0.52$ of FD, and $1843 \mathrm{~nm}$ with an $\mathrm{R}^{2}=0.48$ of SNV (Fig. 4a). For the three group concentration concerning clean, low pollution, and moderate pollution corrected by the natural logarithmic transformation method, the number of rough characteristic bands of the low pollution group was the largest (Fig. 4e), followed by the clean group (Fig. 4d), and moderate pollution group (Fig. 4f). The rough characteristic bands were listed in Table S1. Besides, three transformation methods including CR, FD, and SNV revealed higher sensitivity than other methods for detecting rough characteristic bands for the low pollution group. CR, FD, and SD demonstrated higher sensitivity than other methods for detecting rough characteristic bands for the clean and moderate pollution group. For the clean group, the largest $R^{2}$ was found at $1298\left(R^{2}=0.48\right), 1915\left(R^{2}=0.61\right)$, and $1737\left(R^{2}=0.68\right)$ $\mathrm{nm}$ using $\mathrm{CR}, \mathrm{FD}$, and SD, respectively (Fig. $4 \mathrm{~d}$ ). For the low pollution group, the maximum $\mathrm{R}^{2}$ was found at $2142 \mathrm{~nm}$ with an $\mathrm{R}^{2}$ of 0.53 (CR), $1349 \mathrm{~nm}$ with an $\mathrm{R}^{2}$ of $0.48(\mathrm{FD})$, and $1842 \mathrm{~nm}$ with an $\mathrm{R}^{2}$ of 0.40 (SNV), respectively (Fig. 4e). For the moderate pollution group with the SD transformation method, the largest value was detected at $545 \mathrm{~nm}$ with $\mathrm{R}^{2}$ of 0.64 . Six spectral positions including $2098 \mathrm{~nm}, 1616 \mathrm{~nm}, 846 \mathrm{~nm}, 849 \mathrm{~nm}$, $1084 \mathrm{~nm}$, and $848 \mathrm{~nm}$ appeared peak values ranging from 0.50 to 0.58 (Fig. 4f). For moderate pollution group with other transformation methods (Fig. 4f).

The CWT was implemented on the raw spectral reflectance for spectral transformation, and the Gaussian4 function was selected as the wavelet basis function and the decomposition scales were divided into 10 scales including $2,2^{2}, 2^{3}, 2^{4}, 2^{5}, 2^{6}, 2^{7}, 2^{8}, 2^{9}, 2^{10}\left(\mathrm{~L}_{1}-\mathrm{L}_{10}\right)$. Overall, the $\mathrm{R}^{2}$ values and the number of the rough characteristic bands varied accordingly among the different wavelet decomposition scales. Specifically, the number of the rough characteristic bands was increased with the increasing wavelet decomposition scales excluding $\mathrm{L}_{7}$ and $\mathrm{L}_{8}$, especially for the lab-based processed situation. For lab-based processed situations and low pollution group, the optimal decomposition scales were $\mathrm{L}_{4}, \mathrm{~L}_{5}, \mathrm{~L}_{6}, \mathrm{~L}_{7}$, and $\mathrm{L}_{9}$ according to the $\mathrm{R}^{2}$ values. The rough characteristic bands were listed in Table S2 and were highlighted in red in Fig. 5a and Fig. 5e. On the contrary, for the other four situations including lab-based unprocessed, in-situ, the clean group, and moderate pollution group, the rough characteristic bands were more scattered and less obvious. (Fig. 5b,c,d,f). Moreover, the rough characteristic bands were completely not detected under the conditions of lab-based unprocessed as well as in-situ (Fig. 5b,c). 

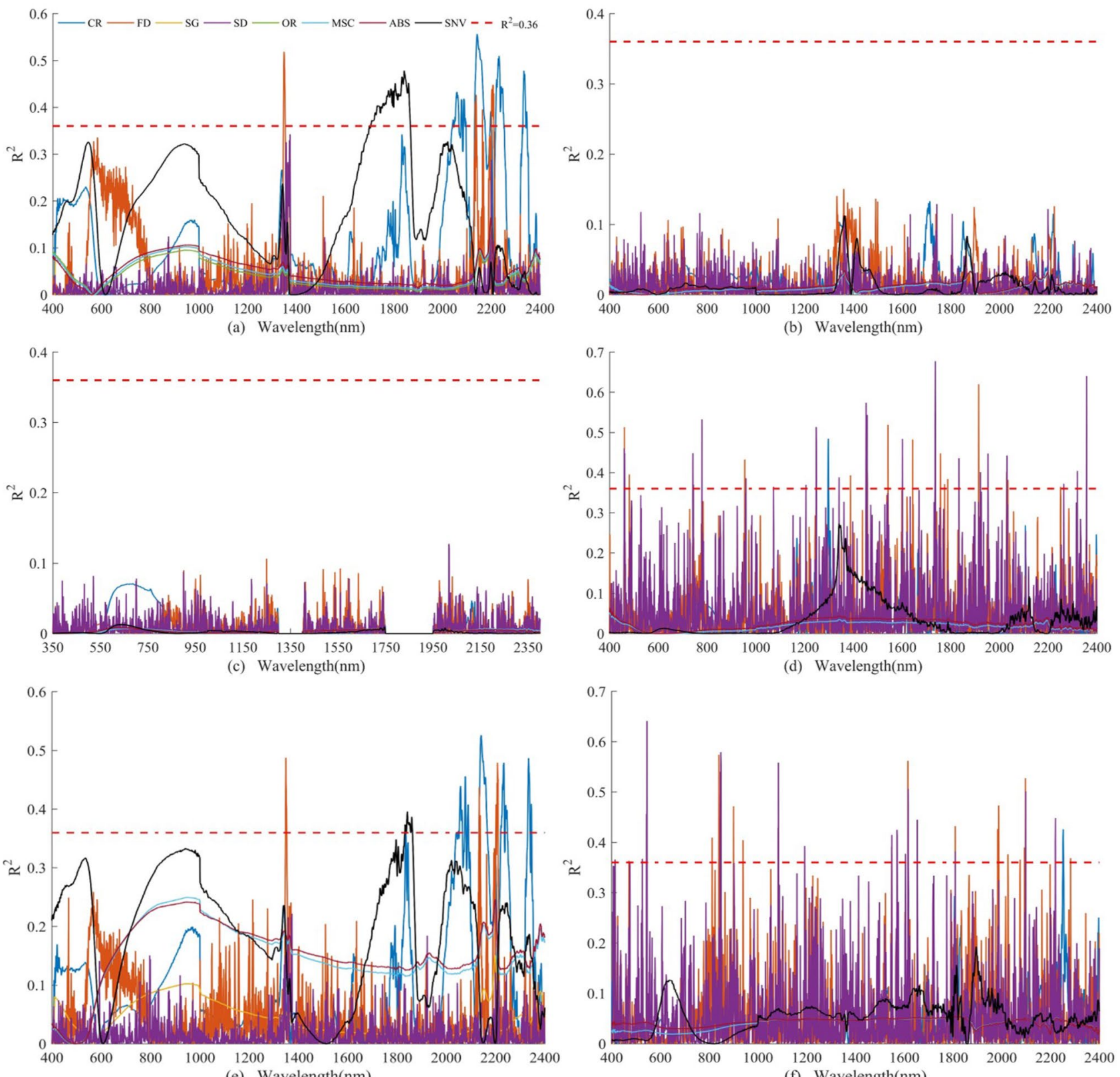

(e) Wavelength $(\mathrm{nm})$

(f) Wavelength(nm)

Figure 4. Correlation of determination $\left(\mathrm{R}^{2}, \mathrm{P}<0.01\right)$ between $\mathrm{Zn}$ concentrations corrected by natural logarithmic transformation and spectral reflectance transformed by CR, FD, SG, SD, MSC, ABS, and SNV under six conditions of soil samples, including (a): lab-based processed, (b): lab-based unprocessed, (c): in-situ, (d): clean group $\left(\mathrm{Zn} \leq 48.6 \mathrm{mg} \mathrm{kg}^{-1}\right)$, (e): low pollution group $\left(48.6 \leq \mathrm{Zn} \leq 97.2 \mathrm{mg} \mathrm{kg}^{-1}\right)$, and (f): moderate pollution group $\left(97.2 \leq \mathrm{Zn} \leq 145.8 \mathrm{mg} \mathrm{kg}^{-1}\right)$. (Note: The spectral reflectance was measured after processing at the laboratory for the clean group, low pollution group, and moderate pollution group.)

For the clean group, the rough characteristic bands were located at positions $\mathrm{L}_{1}, \mathrm{~L}_{2}$, and $\mathrm{L}_{3}$ (Fig. $5 \mathrm{~d}$ ). Specifically, on decomposition scale $\mathrm{L}_{1}$, the rough characteristic bands occurred at 1736, 1242, 744, 1921, 742, 1259, $2158,1501,480$, and $2319 \mathrm{~nm}$. On decomposition scale $\mathrm{L}_{2}$, the rough characteristic bands appeared at 1456, 778, $1541,2032,774$, and $1546 \mathrm{~nm}$. On decomposition scale $\mathrm{L}_{3}$, the rough characteristic bands appeared at $1343 \mathrm{~nm}$. For the moderate pollution group, the rough characteristic bands were situated at the four decomposition scales of $\mathrm{L}_{1}, \mathrm{~L}_{2}, \mathrm{~L}_{3}$, and $\mathrm{L}_{5}$ (Fig. $5 \mathrm{f}$ ). On decomposition scale $\mathrm{L}_{1}$, the rough characteristic bands appeared at 901,544 , 903,1616 , and $1807 \mathrm{~nm}$. On decomposition scale $\mathrm{L}_{2}$, the rough characteristic bands appeared at 1985, 2094, and $2095 \mathrm{~nm}$. On decomposition scale $\mathrm{L}_{3}$, the rough characteristic bands appeared at 1895,1896 , and $2102 \mathrm{~nm}$. On decomposition scale $\mathrm{L}_{5}$, the rough characteristic bands appeared at 2080-2090 $\mathrm{nm}$.

The Boruta algorithm was carried out to determine the optimum characteristic bands for the prediction of $\mathrm{Zn}$ concentrations based on the rough characteristics bands $\left(\mathrm{R}^{2}>0.36\right)$ obtained by Pearson correlation analysis. The important Z-score calculated by the Boruta algorithm of rough characteristics bands were used to choose 
the optimum characteristic bands after lab-based processed for the entire group (Fig. S5), clean group (Fig. S6), the low pollution group (Fig. S7), and the moderate pollution group (Fig. S8).

Clearly, the position and the number of optimal characteristics bands highlighted in green dots changed with transformation methods (Fig. S5). Forty-nine optimal characteristics bands were selected through CR spectral transformation (Fig. S5CR). It was found that 22 spectral variables were important for Zn estimation after the FD spectral transformation, and 1 spectral variable was excluded. Also, 25 characteristic bands were important for predicting Zn content by SNV spectral transformation, and the other 139 bands could be ignored due to the lower Z-score. Meanwhile, there were $6,18,26,28,46,47,45$ characteristics bands for $\mathrm{L}_{2}, \mathrm{~L}_{3}, \mathrm{~L}_{4}, \mathrm{~L}_{5}, \mathrm{~L}_{6}, \mathrm{~L}_{7}$, and $\mathrm{L}_{9}$ respectively through CWT spectral transformation. Then, the optimal characteristics bands were inputted into calibration models as independent variables for estimating $\mathrm{Zn}$ concentration.

Calibrating and comparing Zn concentration based on the PLSR and RF models using optimal characteristic bands of each spectral reflectance transformation method for four sorts of $\mathrm{Zn}$ concentration groups including clean, low pollution, moderate pollution, and the entire samples, respectively. The in-situ and lab-based unprocessed situations were excluded for no characteristic bands were detected according to Sect. 3.3 (Figs. 4, 5). So, the optimal characteristic bands determined by the Boruta algorithm for lab-based processed soil samples were used to calibrate the $\mathrm{Zn}$ concentration corrected by natural logarithmic transformation using RF and PLSR for four groups concerning the entire samples, clean group, low pollution group, and the moderate pollution group. The calibration results for spectral reflectance transformation methods combined with RF and PLSR were compared and evaluated by $\mathrm{R}^{2}$, MAE, RMSE, RPD respectively.

Some reflectance spectra transformation methods were not illustrated in Fig. 6 because the characteristic bands can hardly be retrieved through the above methods. For the entire group, the result of RF based on $\mathrm{L}_{5}$ with relatively higher $\mathrm{R}^{2}\left(\mathrm{R}^{2}=0.83\right)$, $\mathrm{RPD}(\mathrm{RPD}=2.05)$, and lower MAE $\left(\mathrm{MAE}=6.79 \mathrm{mg} \mathrm{kg}^{-1}\right)$, as well as RMSE $\left(\mathrm{RMSE}=9.00 \mathrm{mg} \mathrm{kg}^{-1}\right)$, outperformed PLSR using $\mathrm{L}_{6}$ with lower $\mathrm{R}^{2}\left(\mathrm{R}^{2}=0.72\right)$, $\mathrm{RPD}(\mathrm{RPD}=1.79)$, and higher MAE $\left(\right.$ MAE $\left.=9.30 \mathrm{mg} \mathrm{kg}^{-1}\right)$, RMSE $\left(\right.$ RMSE $\left.=11.71 \mathrm{mg} \mathrm{kg}^{-1}\right)$. RMSECV reached the minimum value when LVs were 4 (Fig. 7a). Besides, the best performance was found as the $\mathrm{RF}\left(\mathrm{ntree}=4, \mathrm{mtry}=3\right.$ ) combined with $\mathrm{L}_{5}$ was trained for estimating $\mathrm{Zn}$ concentration corrected by natural logarithmic transformation (Fig. 6a,b). For the clean group, the result of RF-based on SD with relatively higher $\mathrm{R}^{2}\left(\mathrm{R}^{2}=0.97\right)$, RPD $(\mathrm{RPD}=3.39)$, and lower MAE (MAE $=0.79 \mathrm{mg} \mathrm{kg}^{-1}$ ), as well as RMSE (RMSE $=1.26 \mathrm{mg} \mathrm{kg}^{-1}$ ), was better than PLSR using $\mathrm{L}_{3}$ with lower $\mathrm{R}^{2}$ $\left(\mathrm{R}^{2}=0.73\right)$, RPD $(\mathrm{RPD}=1.52)$ and higher MAE $\left(\mathrm{MAE}=5.37 \mathrm{mg} \mathrm{kg}^{-1}\right)$, RMSE $\left(\mathrm{RMSE}=6.90 \mathrm{mg} \mathrm{kg}^{-1}\right)$. RMSECV reached its minimum value when LVs was 2 (Fig. 7b). Additionally, the optimum robustness has appeared when the RF (ntree =96, mtry =3) combined with SD was fitted (Fig. 6c,d). For the low pollution group, the outcome of RF-based on $\mathrm{L}_{6}$ with relatively higher $\mathrm{R}^{2}\left(\mathrm{R}^{2}=0.83\right)$, $\mathrm{RPD}(\mathrm{RPD}=2.24)$, and lower MAE $\left(\mathrm{MAE}=4.15 \mathrm{mg} \mathrm{kg}^{-1}\right)$, as well as RMSE (RMSE $\left.=4.84 \mathrm{mg} \mathrm{kg}^{-1}\right)$, surpassed PLSR using $\mathrm{L}_{5}$ with lower $\mathrm{R}^{2}\left(\mathrm{R}^{2}=0.68\right)$, $\mathrm{RPD}(\mathrm{RPD}=1.73)$, and higher MAE $\left(\right.$ MAE $\left.=5.99 \mathrm{mg} \mathrm{kg}^{-1}\right)$, RMSE $\left(\right.$ RMSE $\left.=7.21 \mathrm{mg} \mathrm{kg}^{-1}\right)$. Two LVs existed in the PLSR calibration (Fig. 7c). Also, the optimal method for estimating $\mathrm{Zn}$ concentration corrected by natural logarithmic transformation was $\mathrm{RF}(\mathrm{ntree}=3, \mathrm{mtry}=13)$ combined with $\mathrm{L}_{6}(\mathrm{Fig} .6 \mathrm{e}, \mathrm{f})$. For the moderate pollution group, the result of RF-based on $\mathrm{L}_{1}$ with relatively higher $\mathrm{R}^{2}\left(\mathrm{R}^{2}=0.96\right)$, $\mathrm{RPD}(\mathrm{RPD}=3.85)$, and lower $\mathrm{MAE}\left(\mathrm{MAE}=2.54 \mathrm{mg} \mathrm{kg}^{-1}\right)$, as well as RMSE (RMSE $\left.=4.79 \mathrm{mg} \mathrm{kg}^{-1}\right)$, outperformed PLSR using $\mathrm{L}_{1}$ with lower $\mathrm{R}^{2}\left(\mathrm{R}^{2}=0.84\right)$, $\mathrm{RPD}(\mathrm{RPD}=2.10)$, and higher MAE $\left(\right.$ MAE $\left.=7.69 \mathrm{mg} \mathrm{kg}^{-1}\right)$, RMSE $\left(\mathrm{RMSE}=8.37 \mathrm{mg} \mathrm{kg}^{-1}\right)$. Four LVs were determined for PLSR calibration (Fig. 7d). Also, the best method for examing $\mathrm{Zn}$ concentration corrected by natural logarithmic transformation was $\mathrm{RF}$ (ntree $=31$, mtry $=9$ ) combined with $\mathrm{L}_{1}($ Fig. 6g,h).

Overall, RF was better than PLSR no matter which group was trained in estimating $\mathrm{Zn}$ concentration corrected by natural logarithmic transformation. Moreover, the CWT method outperformed the others in the majority of situations (Fig. 6). So, the $\mathrm{L}_{6}$ combine with PLSR (PLSR- $\mathrm{L}_{6}$ ), the $\mathrm{L}_{5}$ combine with RF $\left(\mathrm{RF}-\mathrm{L}_{5}\right.$ ), the $\mathrm{L}_{3}$ combine with PLSR (PLSR- $\mathrm{L}_{3}$ ), the SD combine with RF (RF-SD), the $\mathrm{L}_{5}$ combine with RF (PLSR- $\mathrm{L}_{5}$ ), the $\mathrm{L}_{6}$ combine with RF (RF- $\left.\mathrm{L}_{6}\right)$, the $\mathrm{L}_{1}$ combine with PLSR (PLSR- $\left.\mathrm{L}_{1}\right)$, and the $\mathrm{L}_{1}$ combine with RF $\left(\mathrm{RF}-\mathrm{L}_{1}\right)$ were chosen to map the scatter plot for validating the robustness of each method in examing $\mathrm{Zn}$ concentration corrected by natural logarithmic transformation (Fig. 8) $)^{93}$. Obviously, the best performance was detected in the clean group with the highest validation $\mathrm{R}^{2}\left(\mathrm{R}^{2}=0.97\right), \mathrm{RPD}(\mathrm{RPD}=3.39)$, and relatively lower MAE $\left(\mathrm{MAE}=0.79 \mathrm{mg} \mathrm{kg}^{-1}\right)$, RMSE (RMSE $=1.05 \mathrm{mg} \mathrm{kg}^{-1}$ ) (Fig. 8d). Other results concerning calibration and validation with relatively lower $\mathrm{R}^{2}$, RPD, as well as higher MAE and RMSE were presented in Fig. 8a,b,c,e-g.

\section{Discussion}

The possible reasons for $\mathrm{Zn}$ represented a skewness distribution. The mean $\mathrm{Zn}$ concentration $\left(67.98 \mathrm{mg} \mathrm{kg}^{-1}\right)$ of the study area was larger than the background value of the Inner Mongolia Autonomous Region ( $48.6 \mathrm{mg} \mathrm{kg}^{-1}$ ), which may be led by the coal resources development (Table 1). Moreover, the CV (0.33) indicated that the Zn distribution may be influenced by human activities (Table1). On the one hand, the Zn distribution revealed obvious spatial heterogeneity that the concentration of soil samples close to the mining areas was relatively higher than the distant samples (Fig. 1). The mean content for the soil samples near and off the mining areas was $72.27 \mathrm{mg} \mathrm{kg}^{-1}$, and $56.63 \mathrm{mg} \mathrm{kg}^{-1}$, respectively. On the other hand, the $\mathrm{Zn}$ content may be affected by the distribution of roads in the mining areas because the coal was transported via trucks to the outside and the previous studies proved that one of the major sources for $\mathrm{Zn}$ is the worn tires ${ }^{66}$. So, the skewed distributions of Zn were observed in the current study area (Fig. 3).

The spectral reflectance of the soil samples in the present study area may be affected by the Zn content. Figure S2SG was chosen for describing the character of the soil sample spectral reflectance 


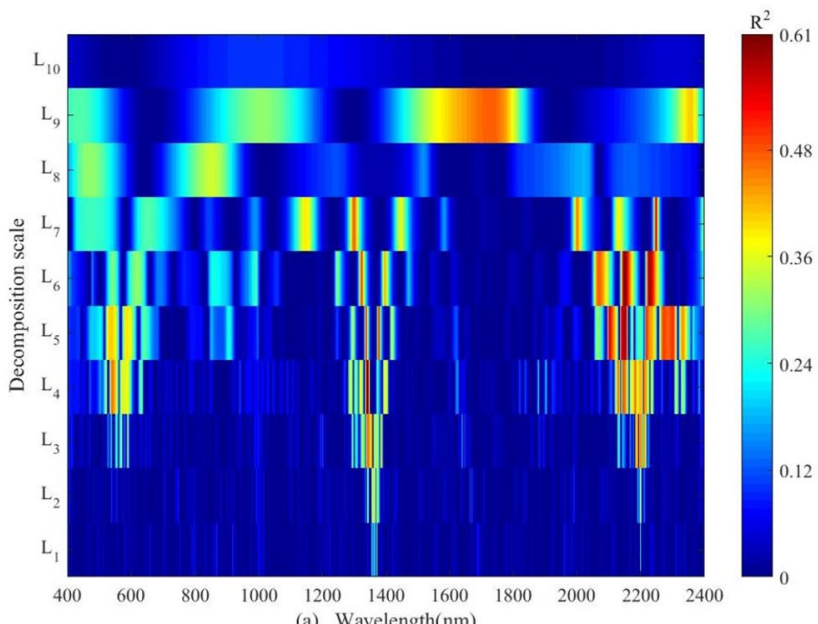

(a) Wavelength(nm)
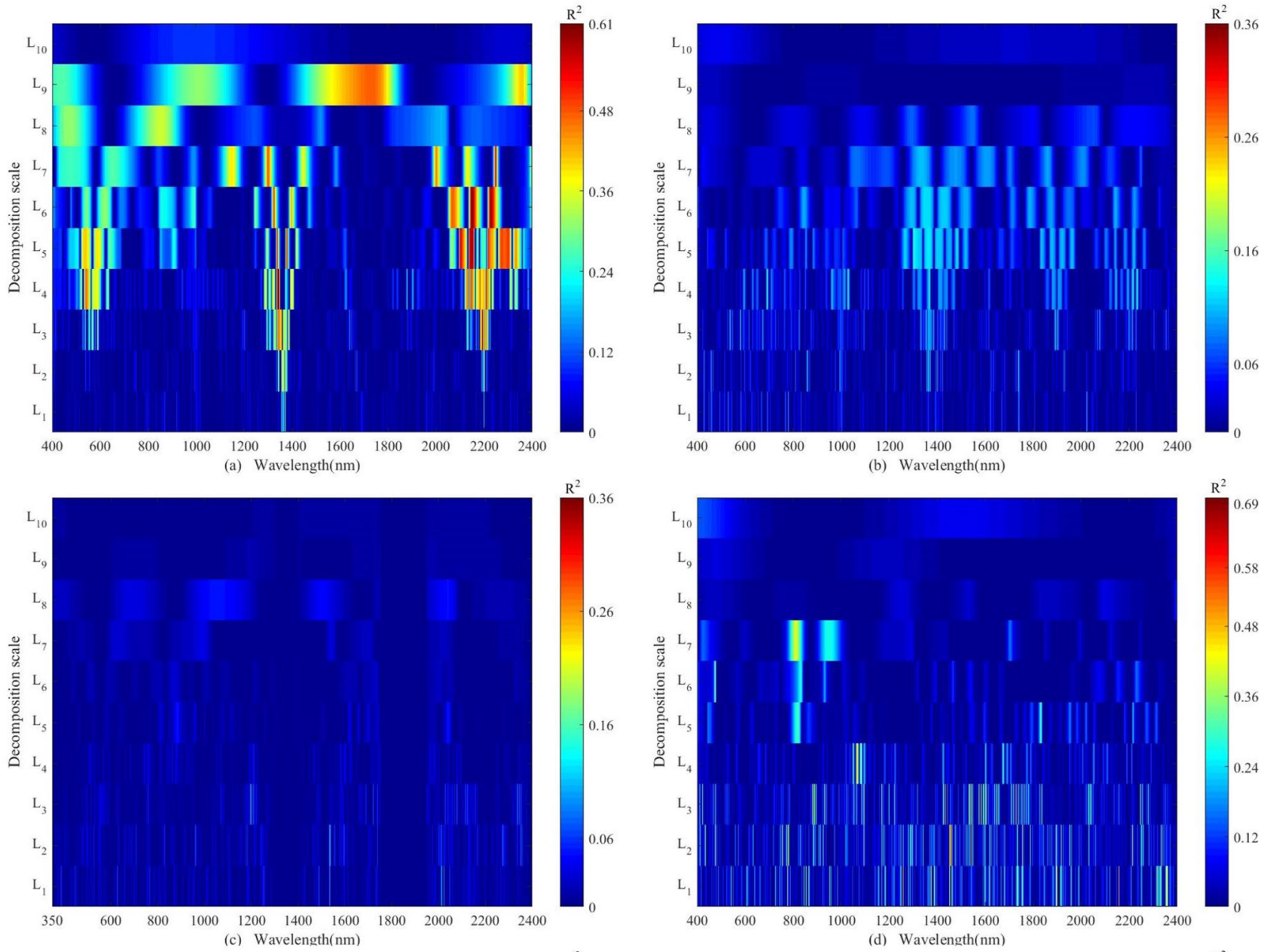

(b) Wavelength(nm)
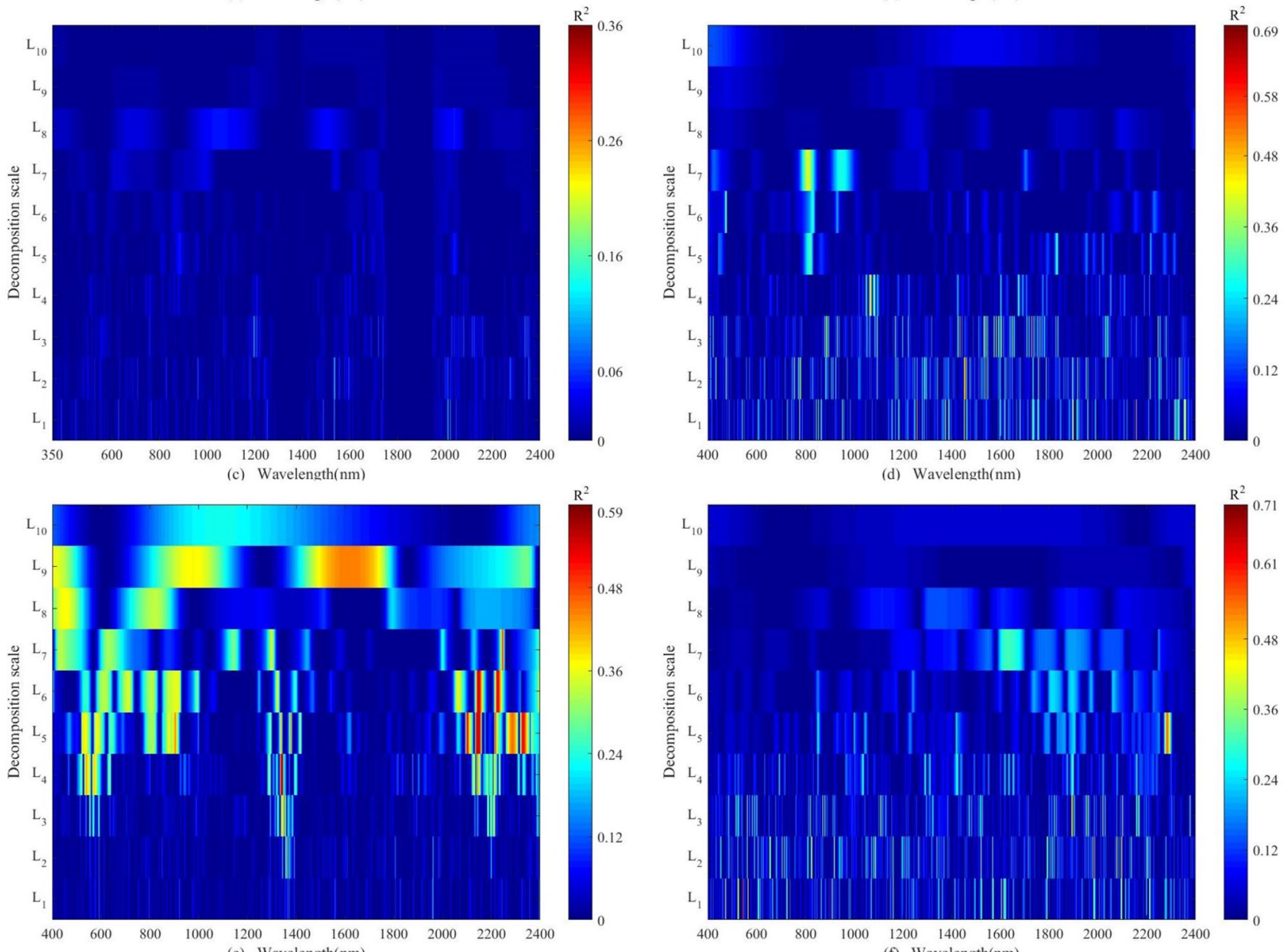

(e) Wavelength(nm)

(f) Wavelength(nm)

Figure 5. Correlation of determination $\left(\mathrm{R}^{2}, \mathrm{P}<0.01\right)$ between $\mathrm{Zn}$ concentrations corrected by natural logarithmic transformation and spectral reflectance transformed by CWT under six conditions of soil samples, including (a):lab-based processed, (b): lab-based processed, (c): in-situ, (d): clean group ( $\left.\mathrm{Zn} \leq 48.6 \mathrm{mg} \mathrm{kg}^{-1}\right),(\mathbf{e})$ : low pollution group $\left(48.6 \leq \mathrm{Zn} \leq 97.2 \mathrm{mg} \mathrm{kg}^{-1}\right)$, and (f): moderate pollution group $\left(97.2 \leq \mathrm{Zn} \leq 145.8 \mathrm{mg} \mathrm{kg}^{-1}\right)$. (Note: The spectral reflectance was measured after processing at the laboratory for the clean group, low pollution group, and moderate pollution group. $\mathrm{L}_{1}-\mathrm{L}_{10}$ denotes the reconstructed spectral reflectance curves based on CWT at decomposition scales of 1-10.) 


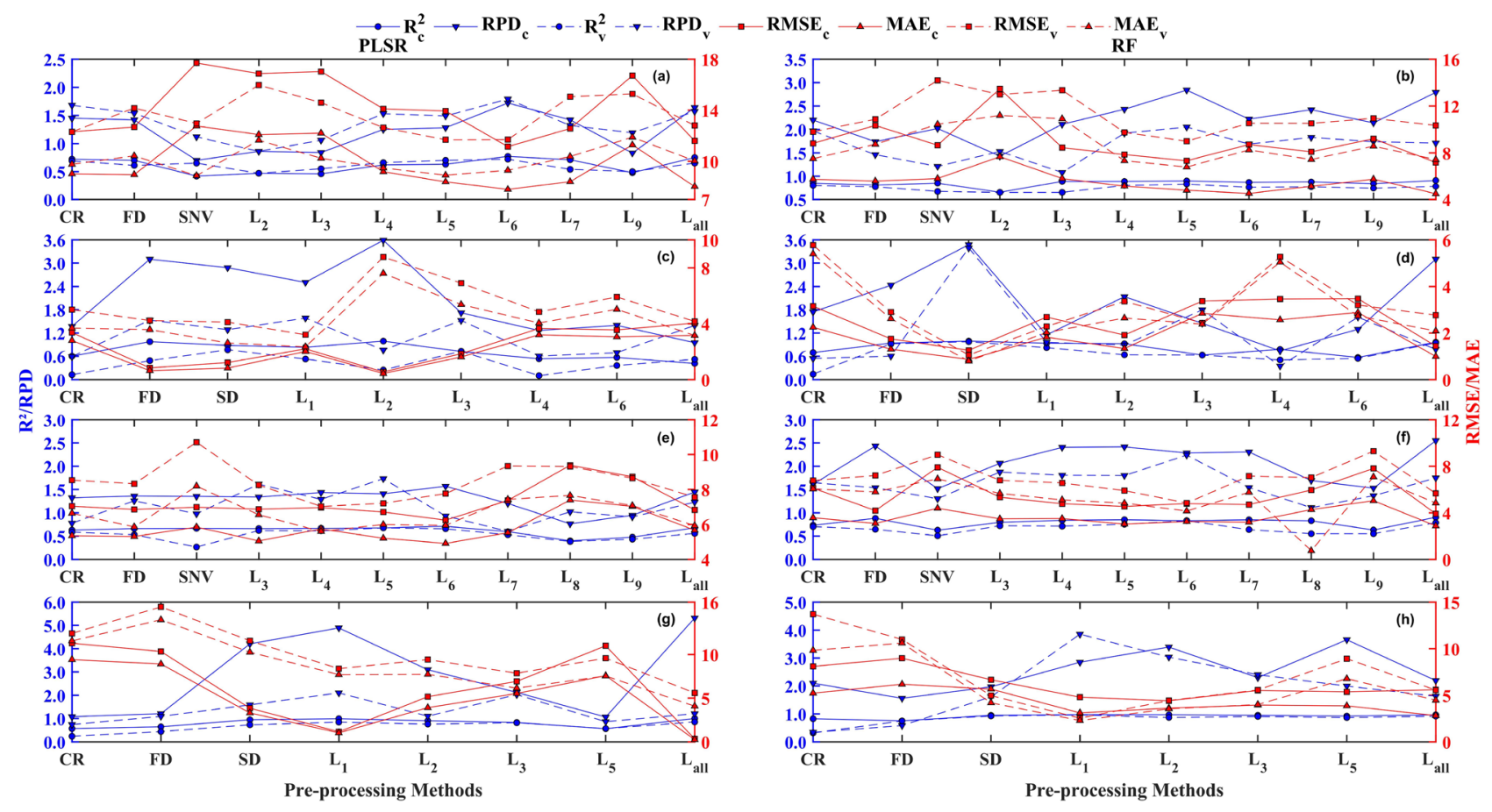

Figure 6. Comparing the performance of calibrating $\mathrm{Zn}$ concentration corrected by natural logarithmic transformation based on different spectral reflectance transformation methods using RF and PLSR at four conditions concerning the entire group, clean group, low pollution group, and moderate pollution group. (a, b): entire samples group, $(\mathbf{c}, \mathbf{d})$ : clean group, $(\mathbf{e}, \mathbf{f})$ : low pollution group, and $(\mathbf{g}, \mathbf{h})$ : moderate pollution group.
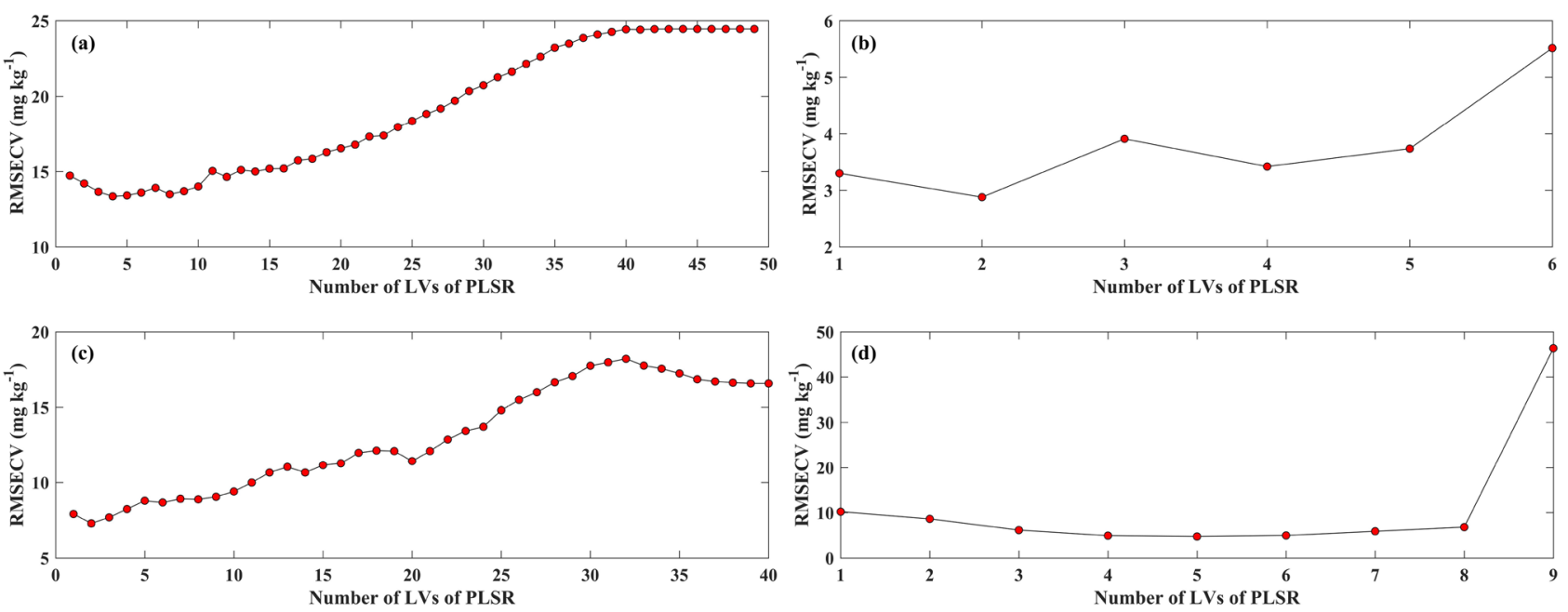

Figure 7. The scatter plots for determining the lowest RMSECV and the corresponding number of LVs. The number of LVs with the lowest RMSECV was used to fit the optimal PLSR in estimating Zn concentrations at four conditions concerning the (a) entire group based on $\mathrm{L}_{6}$, (b) clean group based on $\mathrm{L}_{3}$, (c) low pollution group based on $\mathrm{L}_{5}$, and (d) moderate pollution group based on $\mathrm{L}_{1}$.

because the original spectrum of the soil sample was only smoothed but did not change the basic spectral features by the SG spectral transformation method. Furthermore, Fig. S2SG showed that the spectral reflectance varied with the spectral wavelength and was separated by the content of the $\mathrm{Zn}$, especially during $580-1850 \mathrm{~nm}$. The spectral reflectance was decreased with the $\mathrm{Zn}$ content increasing, that is, the higher content of $\mathrm{Zn}$ exhibited, the lower the spectral reflectance represented. The correspondence results were reported by some published studies. For example, the soil samples from varying metals groups revealed similar spectral features but with variable spectral intensities for the electromagnetic energy was absorbed during some specific wavelength, so the spectral curve changed with the metals content. Overall, the spectral reflectance tended to decrease with the increase in the metals content ${ }^{45}$. Chakraborty et al. ${ }^{91}$ and Douglas et al. ${ }^{94}$ concluded similar characteristics and revealed that polluted soil samples represented a stronger spectral absorbance than the unpolluted soil samples, particularly in the spectral range of $700-2500 \mathrm{~nm}$ which was in line with our results. 
The number of characteristic bands varies with the condition of measuring spectral reflectance, spectral reflectance transformation methods. There were no characteristic bands derived from in-situ and lab-based unprocessed situations in the current study. Contrarily, plenty of characteristic bands were obtained under the lab-based processed condition that implied some possible factors may absorb spectral energy. Soil reflectance spectrum is a cumulative reflection of the physical and chemical properties of soil. Previous studies confirmed that soil properties concerning soil moisture, parent material, organic matter, iron oxides, particle size, mineralogy, and soil structure exhibited significant influence on soil reflectance ${ }^{21,95}$. For the labbased unprocessed and in-situ situation, soil properties such as particle size and moisture content may generate an influence on soil spectral measurement ${ }^{70}$. Besides, the soil surface condition can also affect soil reflectance ${ }^{23}$. Therefore, probable factors that limit the number of characteristic bands under lab-based unprocessed and insitu situations are potential environmental factors. Whereas, for the lab-based processed situation, the soil samples were processed via air-dried, sieved, and grounded into fine particles before spectral surveying to exclude the effect of soil structure, soil moisture, and particle size on spectral characteristics of soil samples.

Clearly, for the lab-based processed situation, the number of characteristic bands based on CWT is obviously larger than other spectral reflectance transformation methods no matter which concentration group and the entire samples were selected for training (Fig. S9). The probable reason why CWT can effectively extract characteristic bands is that CWT offers variable time-frequency resolution that can efficiently and precisely capture time-series information. CWT, with variable size windows, is a windowing technique. Smaller and larger time intervals can be used for analyzing the high and low frequencies through CWT. Both the time domain and the frequency domain were widely used to capture the local patterns of the signal. So, the spectral features could be extracted more effectively via $\mathrm{CWT}^{50}$.

The accuracy for estimating $\mathrm{Zn}$ concentration depends on the pretreatment for the soil samples, spectral reflectance transformation methods, and the calibration models. The accuracy of the calibration for $\mathrm{Zn}$ concentration was discussed in the present study. First, the results demonstrated that the spectral transformation method may influence accuracy. The CWT was the best one than others including CR, FD, SD, SG, ABS, MSC, and SNV in estimating Zn content. Some similar outcomes have also been published in previous studies ${ }^{55,96}$. The possible reason for CWT can improve the accuracy of model estimation was similar to characteristic bands selection discussed in Sect. 4.3. Although the baseline drift caused by the differences in grinding and optical setups can be minimized via MSC and SNV ${ }^{49}$, the benefit is less for the baseline does not change very much. The derivatives can be used in the condition that the low noise level is ensured ${ }^{97}$. In this study, the accuracy of FD and SD was relatively weak because severe noise existing in the original spectrum influenced the valuable information to be extracted ${ }^{45}$. Second, the outcomes revealed that the calibration methods may also affect accuracy. The RF method exhibited significantly higher accuracy than the PLSR in estimating Zn concentration using Vis-NIR spectral data because the relationship between $\mathrm{Zn}$ content and spectral reflectance is not linear but non-linear. Though the PLSR can efficiently deal with the collinearity issue, the capability for solving non-linear relationships is relatively weak ${ }^{53,98}$. The RF model with insensitivity to outliers and excellent generalization ability outperformed PLSR in calibrating Zn concentration. Additionally, the model performance may be influenced by a wide range of target properties ${ }^{99}$. The optimal model for estimating $\mathrm{Zn}$ concentration was the $\mathrm{RF}$ model due to the relatively wide range of $\mathrm{Zn}$ variations in this study $(\mathrm{CV}=0.33)$. On the contrary, the PLSR method had relatively poor applicability when the sample range is very large. Third, the accuracy was also affected by the pretreatment conditions of soil samples ${ }^{45}$. For the in-situ and lab-based unprocessed situations, there were no obvious characteristic bands because soil properties revealed significant influence on soil spectral reflectance resulting in poor capability for calibrating $\mathrm{Zn}$ concentrations.

The soil samples were divided into three groups according to the $\mathrm{Zn}$ content including clean, low pollution, and moderate pollution groups to test the calibration results that were influenced by the concentration of $\mathrm{Zn}$ or not. The accuracy was promoted with the $\mathrm{Zn}$ concentration increasing when the $\mathrm{CWT}$ with $\mathrm{L}_{3}$ scale was selected to fit the RF model (Fig. 6d,f,h). Whereas, the accuracy represented decreasing trend with the $\mathrm{Zn}$ concentration increasing no matter which calibration methods we used when the FD was chosen to run the model (Fig. 6c-h). So, the accuracy of calibration may not be affected by the content of $\mathrm{Zn}$.

The relationship between the accuracy of the calibration model and the number of characteristic bands was not significant. However, the accuracy may be improved through retrieving characteristic bands with highly $\mathrm{R}^{2}$ that played an important role in calibrating Zn content (Figs. 4, 5, 6). The characteristic bands with the highest $R^{2}$ appeared in the results of the moderate pollution group $\left(R^{2}=0.71\right)$, followed by the clean group $\left(R^{2}=0.69\right)$, the entire samples group $\left(R^{2}=0.61\right)$, and the low pollution group $\left(R^{2}=0.59\right)$. The $R^{2}$ for the model validation were $0.96,0.83,0.97$, and 0.83 for the moderate pollution group, the clean group, the entire samples group, and the low pollution group, respectively.

Overall, we speculated that the accuracy of calibration may be influenced by spectral reflectance transformation methods, calibration methods, the condition for measuring soil spectrum, and the characteristic bands with highly $\mathrm{R}^{2}$ that were used to describe the relationship between the $\mathrm{Zn}$ content and the reflectance spectra after transforming. However, the content of $\mathrm{Zn}$, the number of the samples, and the number of the characteristic bands excluding the results obtained from RF represented a relatively weak effect in the accuracy of estimating Zn content.

The possible reasons for the important bands in estimating $\mathrm{Zn}$ concentrations based on PLSR and RF models using Vis-NIR spectra. Several important bands for the optimal PLSR including 1534, $1540,1541,1807,1985,1989,2148-2155,2224-2243,2328,2331-2338,2341,2399$, and $2400 \mathrm{~nm}$ were proved their importance for Zn estimation (Fig. 9a-d). For the optimum RF model, 460, 901, 1336, 1340, 1341, 1457, 

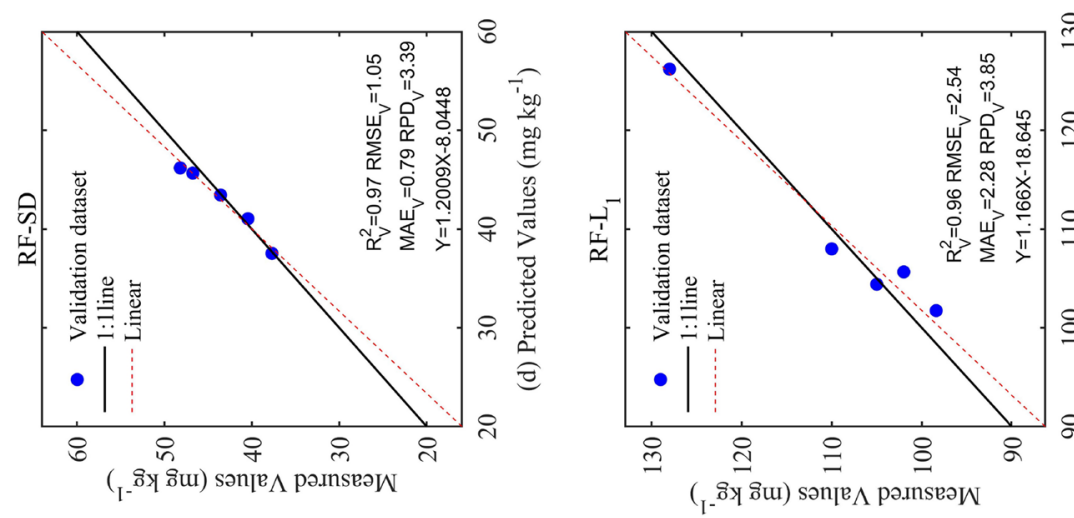

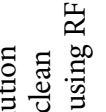
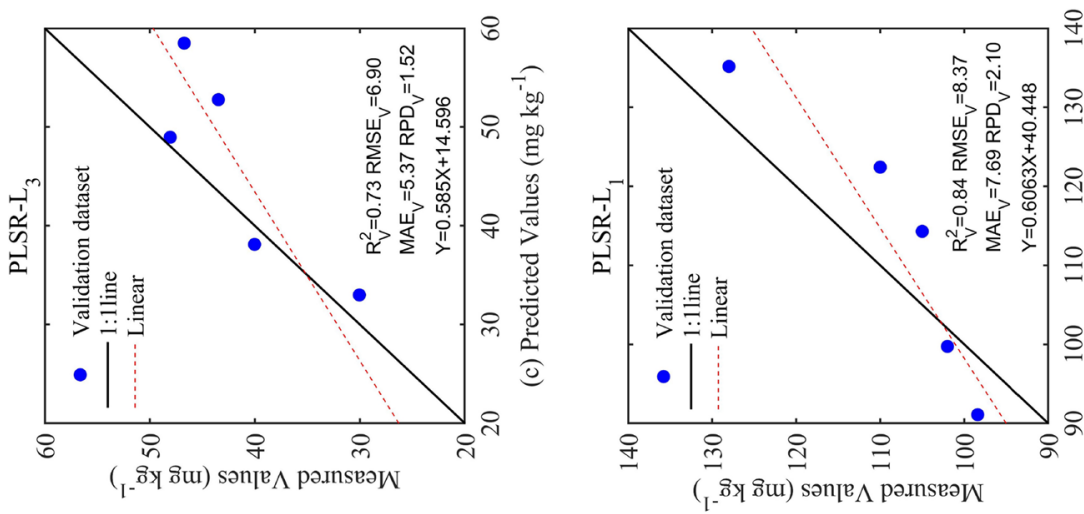

¿ํㅝ

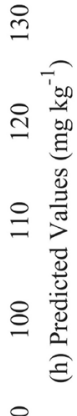

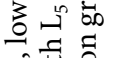

\&

乙

크릉

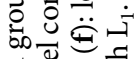

है छิ

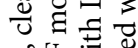

互空高

II $\cong .00$
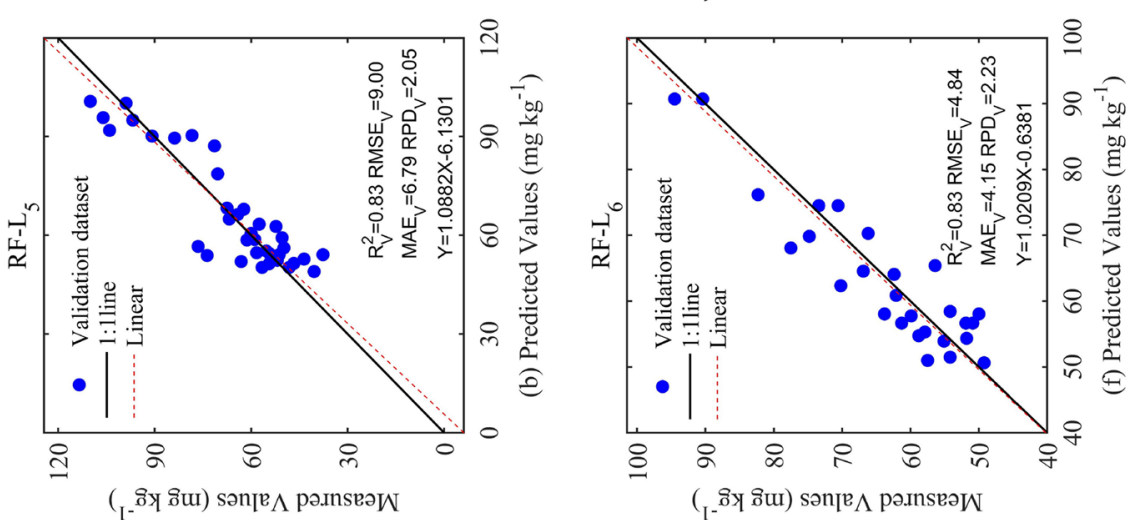

节言

की

so \&

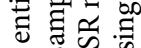

\&

承苛

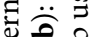

웅

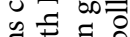

.0ี

휼

킁으

웡

记

चू

青焉

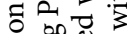

氙 $\cong$

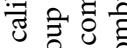

उี कूष्ठ

\&

을 岂

I

을

嵌
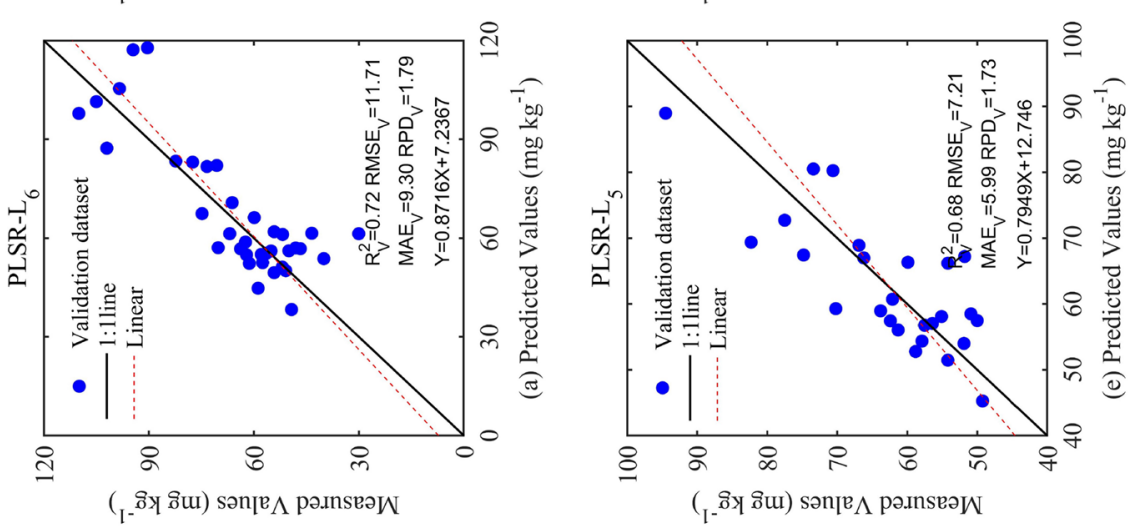

둥

율 은

Z艺

웡.

ठํㅟ

도을

00.03

吾吾

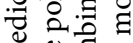

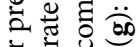

केष

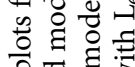

듬

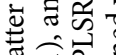

चु

$\infty$ 乙

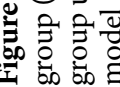



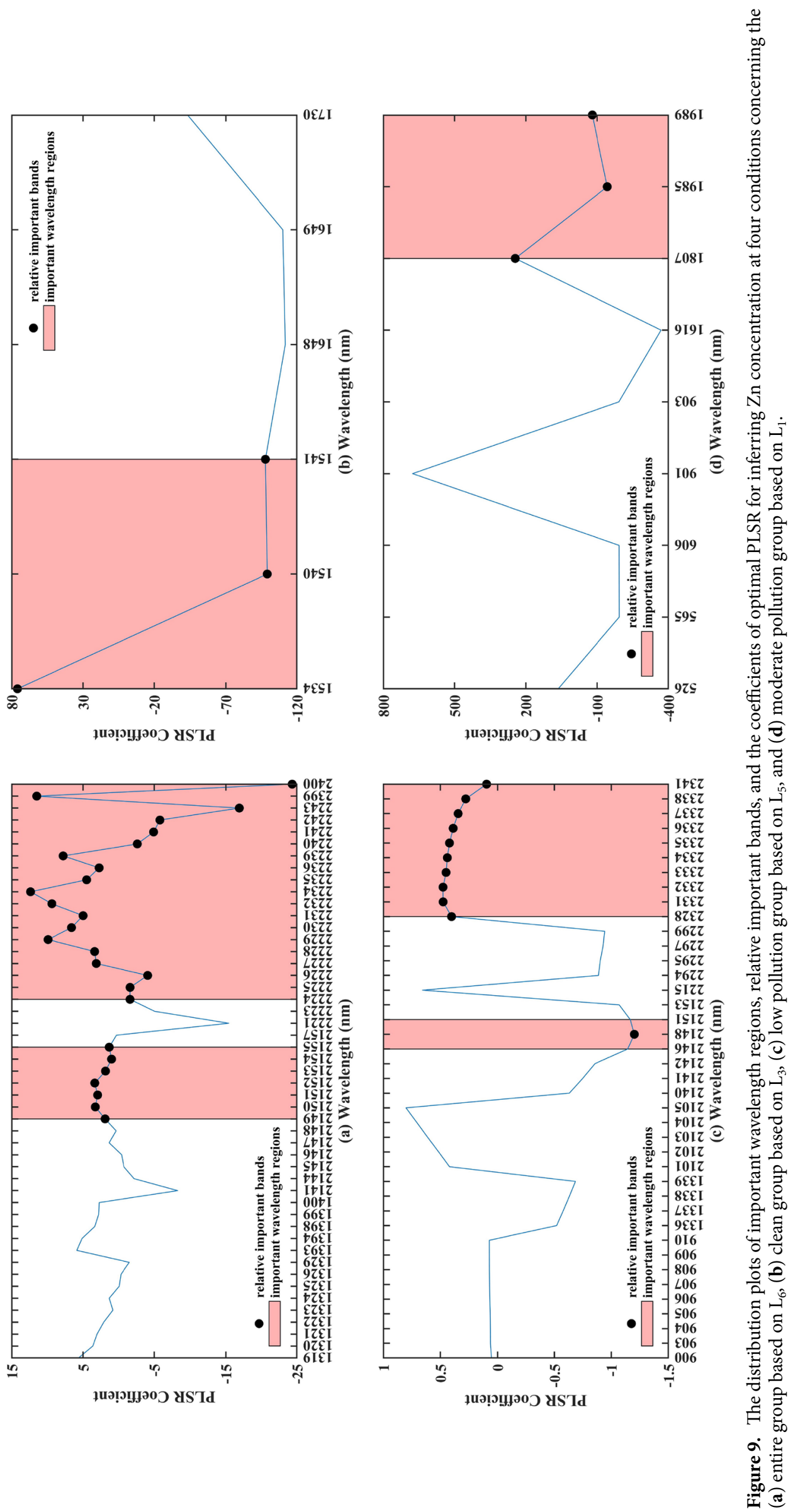

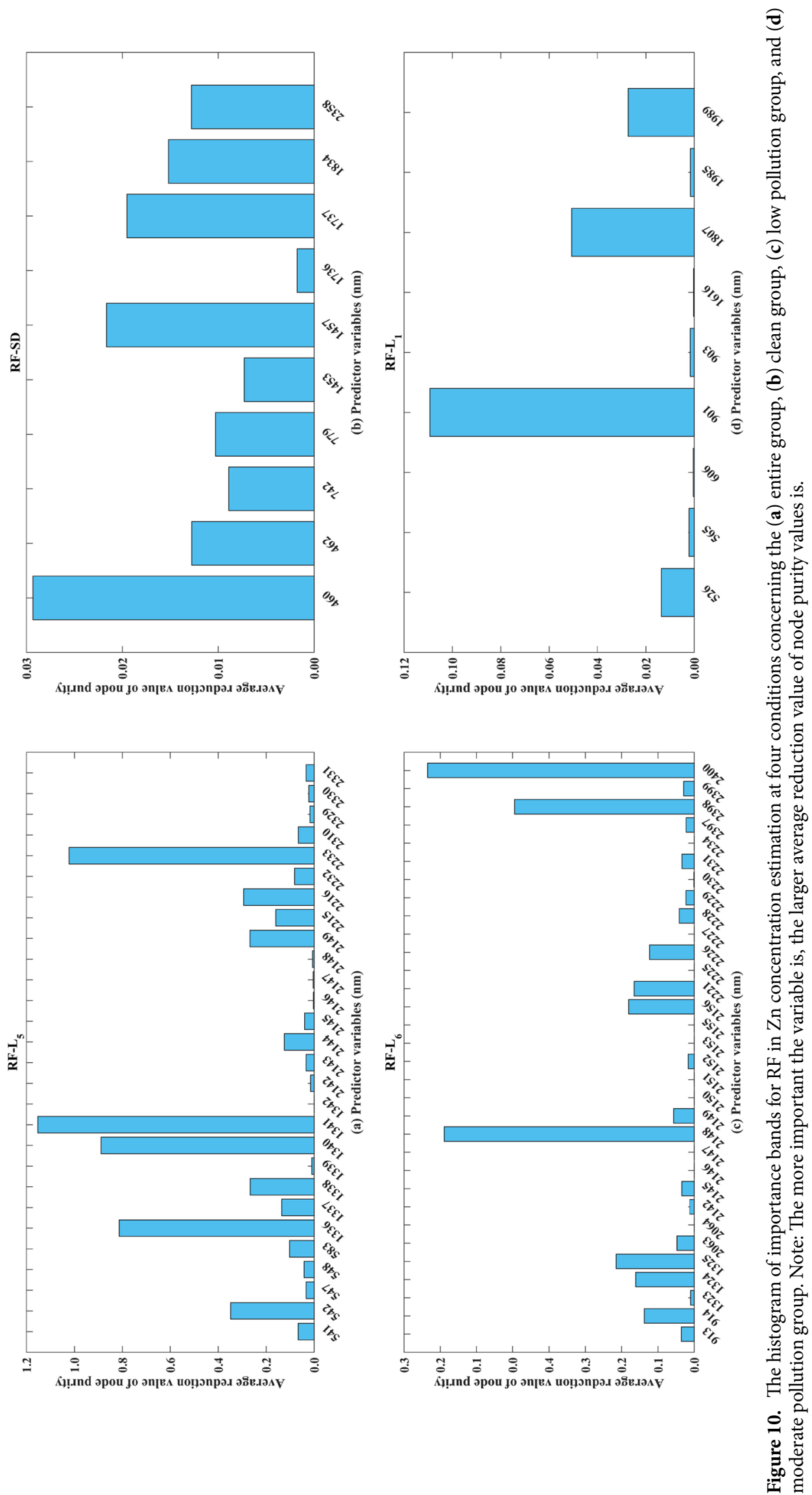
1737, 1807, 1834, 1989, 2148, 2233, 2398, and $2400 \mathrm{~nm}$ were identified as the relative important bands (Fig. 10ad). To our knowledge, clay minerals demonstrated the strong adsorption of $\mathrm{Zn}$ around 1400, 1900, and 2200 $\mathrm{nm}^{87}$. Specifically, the spectral reflectance features of clay minerals demonstrated kaolinite spectrum had an obvious feature owing to a hydroxyl absorption wavelength with aluminum coordination at around $2200 \mathrm{~nm}$. Two significant absorption regions about $1400 \mathrm{~nm}$ and $1900 \mathrm{~nm}$ were detected for vermiculite had interlayer moisture. Furthermore, a previous study proved that spectral bands associated with organic matter and clay minerals can be used for inferring Zn concentration with relatively high estimation accuracy ${ }^{87}$. Meanwhile, an experiment designed for exploring the relationship between heavy metals and soil constituents confirmed $\mathrm{Zn}$ was easily absorbed on soil mineral constituents, especially montmorillonite and vermiculite under the competitive environment ${ }^{100}$. Moreover, published researches confirmed that soil organic matter and goethite also represented obvious adsorption of $\mathrm{Zn}$ at $400-800 \mathrm{~nm}$ and 420 and $950 \mathrm{~nm}$,respectively ${ }^{45,101}$.

Research limitations and future research plans. There are some problems that need to be further addressed. First, the current study was a local research, not a global finding, the methods used in the present study may exist drawbacks due to the universal application. Second, though the calibration models for inferring heavy metals concentrations were obtained, the models of this study only can be used to estimate the heavy metals concentrations at sampling sites. Obtaining continuous heavy metals concentrations distribution is strongly desired. So, exploring calibration models using space-borne and airborne sensing combined with the ground level models based on in-situ sampling sites is still a big challenge. Third, some related soil properties concerning the soil texture, $\mathrm{pH}$, salt, organic matter, clay minerals, and the presence of other heavy metals, combined with natural environmental factors, such as soil parent material and soil formation conditions were ignored in the current study. So, the accuracy of this study needs to be improved. Fourth, the present study only constructed the calibration model for the Zn element. Other toxic metals need to be studied in the future. Fifth, the spectral response of heavy metals was very weak for heavy metals in soils are truly a minute component comparing with water, organic matter, and clay minerals. It is impossible to detect the spectral signal of some metals unless their content exceeds $4.0 \mathrm{mg} \mathrm{g}^{-1}$. So, we plan to deep dive into this orientation as follows. First, the space-borne and airborne sensing products will be implemented to retrieve the metals distribution at large scales. In the future, we plan to (1) utilize a direct standardization algorithm for establishing a transfer model of soil spectra between laboratory obtained and GaoFen- 5 image obtained to inverse the soil heavy metals concentrations, and (2) to obtain the continuous distribution map of the soil heavy metals concentrations based on the optimal estimation model determined by the RF, extreme learning machine (ELM), support vector machine (SVM), and back-propagation neural network (BPNN) algorithms for the study area. Second, the related soil properties will be considered in the next research for improving accuracy. Third, we plan to continually develop methods in improving the accuracy of the calibration model using novel deep learning methods. In general, the mechanism of metals concentrations is very complicated, and the metals concentrations may be affected by both anthropic and natural factors. Moreover, the relations of metals concentrations with soil properties are still not very clear. Although pure metals were hard to sorb vis-NIR and mid-IR radiation, the correlated relationship between heavy metals concentrations and organic matter as well as clay minerals can be used for inversing heavy metals indrectly. Fourth, $\mathrm{Ni}, \mathrm{Cu}$, and $\mathrm{Pb}$ will be considered in the future due to the serious toxicity. Meanwhile, the $\mathrm{Cr}$ element will be also chosen as the objective because the $\mathrm{Cr}$ element was considered as common heavy metals pollutants in an open pit coal mine. Overall, it is still a huge challenge to conduct a multidisciplinary study in estimating metals concentrations.

\section{Conclusion}

The present study revealed that Vis-NIR spectroscopy can be used to calibrate Zn concentration in topsoils of open cast coal mining areas. Overall, the spectral reflectance tended to decrease with the increase of the $\mathrm{Zn}$ content during $580^{-1} 850 \mathrm{~nm}$ based on SG smoothing. CWT could retrieve more detailed spectral characteristics than other methods mainly because CWT can offer variable time-frequency resolution that can efficiently and precisely capture time-series information. The RF combined with CWT demonstrated the optimal accuracy than other methods in the current study (calibration: $\mathrm{R}^{2}=0.99, \mathrm{RPD}=3.47, \mathrm{RMSE}=1.26 \mathrm{mg} \mathrm{kg}{ }^{-1}, \mathrm{MAE}=0.86 \mathrm{mg} \mathrm{kg}^{-1}$; validation: $\mathrm{R}^{2}=0.97, \mathrm{RPD}=3.39$, $\mathrm{RMSE}=1.05 \mathrm{mg} \mathrm{kg}^{-1}, \mathrm{MAE}=0.79 \mathrm{mg} \mathrm{kg}^{-1}$ ). The accuracy of estimating $\mathrm{Zn}$ content may be hardly affected by the content of $\mathrm{Zn}$, the number of the samples, and the number of the characteristic bands excluding the results obtained from RF. This study will help to develop an effective technique to speedily detect metals concentration in possible contaminated areas such as coal mines and metallic mineral deposit areas.

Received: 12 May 2021; Accepted: 2 September 2021

Published online: 07 October 2021

\section{References}

1. Jiang, X., Lu, W. X., Zhao, H. Q., Yang, Q. C. \& Yang, Z. P. Potential ecological risk assessment and prediction of soil heavy-metals pollution around coal gangue dump. Nat. Hazard. Earth Syst. 2, 1977-2010 (2014).

2. Wang, Q. \& Li, R. Decline in Chinass coal consumption: An evidence of peak coal or a temporary blip?. Energ. Policy 108, 696-701 (2017).

3. Li, W. et al. Addressing the $\mathrm{Co} 2$ emissions of the world's largest coal producer and consumer: Lessons from the Haishiwan coalfield, China. Energy 80, 400-413 (2015).

4. Luo, P. et al. Water quality trend assessment in Jakarta: A rapidly growing Asian megacity. Plos One 14, e219009 (2019).

5. Luo, P. et al. Flood inundation assessment for the Hanoi Central Area, Vietnam under historical and extreme rainfall conditions. Sci. Rep. Uk. 8, 12623 (2018). 
6. Guo, B. et al. Determining the effects of socioeconomic and environmental determinants on chronic obstructive pulmonary disease (Copd) mortality using geographically and temporally weighted regression model across Xi'an During 2014-2016. Sci. Total Environ. 756, 143869 (2021).

7. Pei, L., Wang, X., Guo, B., Guo, H. \& Yu, Y. Do air pollutants as well as meteorological factors impact corona virus disease 2019 (Covid-19)? Evidence from China based on the geographical perspective. Environ. Sci. Pollut. R. 28, 35584-35596 (2021).

8. Chen, T., Chang, Q., Liu, J., Clevers, J. G. P. W. \& Kooistra, L. Identification of soil heavy metals sources and improvement in spatial mapping based on soil spectral information: A Case Study in Northwest China. Sci. Total Environ. 565, 155-164 (2016).

9. Li, Z., Ma, Z., Kuijp, T. J. V. D., Yuan, Z. \& Huang, L. A review of soil heavy metals pollution from mines in China: Pollution and health risk assessment. Sci. Total Environ. 468, 843-853 (2014).

10. Wang, L. et al. A comprehensive mitigation strategy for heavy metals contamination of farmland around mining areas-screening of low accumulated cultivars, soil remediation and risk assessment. Environ. Pollut. 245, 820-828 (2019).

11. Siddiqui, A. U., Jain, M. K. \& Masto, R. E. Pollution evaluation, spatial distribution, and source apportionment of trace metals around coal mines soil: The Case Study of Eastern India. Environ. Sci. Pollut. R. 27, 10822-10834 (2020).

12. Guo, D., Bai, Z., Shangguan, T., Shao, H. \& Qiu, W. Impacts of coal mining on the aboveground vegetation and soil quality: A case study of Qinxin Coal Mine in Shanxi Province, China. Clean Soil Air Water. 39, 219-225 (2011).

13. Woodworth, M. D. Frontier Boomtown Urbanism in Ordos, Inner Mongolia Autonomous Region. Cross Curr. East Asian Hist. Cult. Rev. 1, 74-101 (2012).

14. Zeng, X., Liu, Z., He, C., Ma, Q. \& Wu, J. Quantifying Surface coal-mining patterns to promote regional sustainability in Ordos, Inner Mongolia. Sustain. Basel. 10, 1135 (2018).

15. Bu, Q. et al. Concentrations, spatial distributions, and sources of heavy metals in surface soils of the Coal Mining City Wuhai, China. J. Chem. Ny. 2020, 1-10 (2020)

16. Hou, L., Li, X. \& Li, F. Hyperspectral-based inversion of heavy metals content in the soil of coal mining areas. J. Environ. Qual. 48, 57-63 (2019).

17. Liu, X., Bai, Z., Zhou, W., Cao, Y. \& Zhang, G. Changes in soil properties in the soil profile after mining and reclamation in an opencast coal mine on the loess plateau, China. Ecol. Eng. 98, 228-239 (2017).

18. Liu, X., Shi, H., Bai, Z., Zhou, W. \& He, Y. Heavy metals concentrations of soils near the large opencast coal mine pits in China. Chemosphere. 244, 125360 (2019).

19. Gabriel, et al. Amending potential of organic and industrial by-products applied to heavy metals-rich mining soils. Ecotox. Environ. Safe. 162, 581-590 (2018).

20. Zhai, X. et al. Remediation of multiple heavy metals-contaminated soil through the combination of soil washing and in situ immobilization. Sci. Total Environ. 635, 92-99 (2018).

21. Wang, F., Gao, J. \& Zha, Y. Hyperspectral sensing of heavy metals in soil and vegetation: Feasibility and challenges. ISPRS J. Photogramm. 136, 73-84 (2018).

22. Shi, T., Chen, Y., Liu, Y. \& Wu, G. Visible and near-infrared reflectance spectroscopy-an alternative for monitoring soil contamination by heavy metals. J. Hazard. Mater. 265, 166-176 (2014).

23. Zou, B., Jiang, X., Feng, H., Tu, Y. \& Tao, C. Multisource spectral-integrated estimation of cadmium concentrations in soil using a direct standardization and spiking algorithm. Sci. Total Environ. 701, 134890 (2020).

24. Guan, Q. et al. Source apportionment of heavy metals in agricultural soil based on Pmf: A case study in Hexi Corridor, Northwest China. Chemosphere 193, 189-197 (2017).

25. Horta, A. et al. Potential of integrated field spectroscopy and spatial analysis for enhanced assessment of soil contamination: A prospective review. Geoderma 241, 180-209 (2015).

26. Saqib, et al. Efficiency and surface characterization of different plant derived biochar for cadmium (Cd) mobility, bioaccessibility and bioavailability to Chinese cabbage in highly contaminated soil. Chemosphere 211, 632-639 (2018).

27. Wei, L. et al. An improved gradient boosting regression tree estimation model for soil heavy metals (arsenic) pollution monitoring using hyperspectral remote sensing. Appl. Sci. Basel. 9, 1943 (2019).

28. Ngole-Jeme, V. M. Heavy metals in soils along unpaved roads in south west Cameroon: Contamination levels and health risks. Ambio 3, 374-386 (2016).

29. Huang, Y. et al. Heavy metals pollution and health risk assessment of agricultural soils in a typical Peri-Urban area in Southeast China. J. Environ. Manage. 207, 159-168 (2018).

30. Bruce, P. et al. Low-level lead exposure and mortality in Us adults: A population-based cohort study. Lancet Public Health. 3, 177-184 (2018).

31. Harari, F. et al. Blood lead levels and decreased kidney function in a population-based cohort. Am. J. Kidney Dis. 72, 381-389 (2018).

32. Sun, W., Zhang, X., Sun, X., Sun, Y. \& Cen, Y. Predicting Nickel concentration in soil using reflectance spectroscopy associated with organic matter and clay minerals. Geoderma 327, 25-35 (2018).

33. Guan, Q. et al. Prediction of heavy metals in soils of an arid area based on multi-spectral data. J. Environ. Manag. 243, 137-143 (2019).

34. Lin, X. et al. Geographically weighted regression effects on soil zinc content hyperspectral modeling by applying the fractionalorder differential. Remote Sens. Basel. 11, 636 (2019).

35. Leenaers, H., Okx, J. P. \& Burrough, P. A. Employing elevation data for efficient mapping of soil pollution on floodplains. Soil Use Manag. 6, 105-114 (2010).

36. De Jesus, A., Zmozinski, A. V., Damin, I. C. F., Silva, M. M. \& Vale, M. G. R. Determination of arsenic and cadmium in crude oil by direct sampling graphite furnace atomic absorption spectrometry. Spectrochim. Acta B 71, 86-91 (2012).

37. Zhang, X., Sun, W., Cen, Y., Zhang, L. \& Wang, N. Predicting cadmium concentration in soils using laboratory and field reflectance spectroscopy. Sci. Total Environ. 650, 321-334 (2019).

38. Harun, C., Mursit, T. M. \& Esen, C. Simultaneous preconcentration and determination of Ni and $\mathrm{Pb}$ in water samples by solidphase extraction and flame atomic absorption spectrometry. J. Aoac Int. 96, 875-879 (2013).

39. Gholizadeh, A., Saberioon, M., Ben-Dor, E. \& Borůvka, L. Monitoring of selected soil contaminants using proximal and remote sensing techniques: background, state-of-the-art and future perspectives. Crit. Rev. Env. Sci. Technol. 48, 243-278 (2018).

40. Wei, L., Yuan, Z., Yu, M., Huang, C. \& Cao, L. Estimation of arsenic content in soil based on laboratory and field reflectance spectroscopy. Sensors-Basel. 19, 3904 (2019).

41. Chen, T., Chang, Q., Clevers, J. G. P. W. \& Kooistra, L. Rapid identification of soil cadmium pollution risk at regional scale based on visible and near-infrared spectroscopy. Environ. Pollut. 206, 217-226 (2015).

42. Liu, G. et al. Partitioning and geochemical fractions of heavy metals from geogenic and anthropogenic sources in various soil particle size fractions. Geoderma 312, 104-113 (2018).

43. Meng, X. et al. Regional soil organic carbon prediction model based on a discrete wavelet analysis of hyperspectral satellite data. Int. J. Appl. Earth Obs. 89, 102111 (2020).

44. Hong, Y. et al. Exploring the potential of airborne hyperspectral image for estimating topsoil organic carbon: Effects of fractionalorder derivative and optimal band combination algorithm. Geoderma. 365, 114228 (2020).

45. Hong, Y. et al. Estimating lead and zinc concentrations in Peri-Urban agricultural soils through reflectance spectroscopy: Effects of fractional-order derivative and random forest. Sci. Total Environ. 651, 1969-1982 (2019). 
46. Wang, J. et al. Prediction of low heavy metals concentrations in agricultural soils using visible and near-infrared reflectance spectroscopy. Geoderma 216, 1-9 (2014).

47. Jiang, Q., Liu, M., Wang, J. \& Liu, F. Feasibility of using visible and near-infrared reflectance spectroscopy to monitor heavy metals contaminants in Urban lake sediment. CATENA 162, 72-79 (2018).

48. Khosravi, V., Doulati Ardejani, F., Yousefi, S. \& Aryafar, A. Monitoring soil lead and zinc contents via combination of spectroscopy with extreme learning machine and other data mining methods. Geoderma 318, 29-41 (2018).

49. Cheng, H. et al. Estimating heavy metals concentrations in suburban soils with reflectance spectroscopy. Geoderma 336, 59-67 (2019).

50. Zhang, S. et al. Hyperspectral inversion of heavy metals content in reclaimed soil from a mining wasteland based on different spectral transformation and modeling methods. Spectrochim. Acta A 211, 393-400 (2019).

51. Gholizadeh, A., Saberioon, M., Carmon, N., Boruvka, L. \& Ben-Dor, E. Examining the performance of Paracuda-Ii data-mining engine versus selected techniques to model soil carbon from reflectance spectra. Remote Sens.-Basel. 10, 1172 (2018).

52. Tian, S. et al. Hyperspectral prediction model of metals content in soil based on the genetic ant colony algorithm. SustainabilityBasel. 11, 3197 (2019).

53. Xu, S., Zhao, Y., Wang, M. \& Shi, X. Comparison of multivariate methods for estimating selected soil properties from intact soil cores of paddy fields by Vis-Nir spectroscopy. Geoderma 310, 29-43 (2018).

54. Tao, C. et al. A transferable spectroscopic diagnosis model for predicting arsenic contamination in soil. Sci. Total Environ. 669, 964-972 (2019).

55. Lu, Q. et al. Rapid inversion of heavy metals concentration in Karst grain producing areas based on hyperspectral bands associated with soil components. Microchem. J. 148, 404-411 (2019).

56. Tan, K. et al. Estimation of the spatial distribution of heavy metals in agricultural soils using airborne hyperspectral imaging and random forest. J. Hazard. Mater. 382, 120987 (2020).

57. Chen, S. et al. Fine resolution map of top- and subsoil carbon sequestration potential in France. Sci. Total Environ. 630, 389-400 (2018).

58. Tan, K. et al. Estimating the distribution trend of soil heavy metals in mining area from hymap airborne hyperspectral imagery based on ensemble learning. J. Hazard. Mater. 401, 123288 (2021).

59. Mao, X., Meng, J. \& Xiang, Y. Cellular automata-based model for developing land use ecological security patterns in semi-arid areas: A case study of Ordos, Inner Mongolia, China. Environ. Earth Sci. 70, 269-279 (2013).

60. Ramirez-Lopez, L. et al. Sampling optimal calibration sets in soil infrared spectroscopy. Geoderma 226, 140-150 (2014).

61. Liu, W., Zhao, J., Ouyang, Z., Söderlund, L. \& Liu, G. Impacts of sewage irrigation on heavy metals distribution and contamination in Beijing, China. Environ. Int. 31, 805-812 (2005)

62. Keshavarzi, A. \& Kumar, V. Ecological risk assessment and source apportionment of heavy metals contamination in agricultural soils of Northeastern Iran. Int. J. Environ. Heal. R. 29, 544-560 (2018).

63. Salminen, R. et al. Geochemical mapping field manual, Espoo, Finland Geological Survey of Finland. Geol. Surv. Den. Greenl. 38, 1-20 (1998).

64. Sun, W., Skidmore, A. K., Wang, T. \& Zhang, X. Heavy metals pollution at mine sites estimated from reflectance spectroscopy following correction for skewed data. Environ. Pollut. 252, 1117-1124 (2019).

65. Guo, B. et al. Ecological risk evaluation and source apportionment of heavy metals in park playgrounds: A case study in Xi'an, Shaanxi Province, a Northwest City of China. Environ. Sci. Pollut. R. 27, 24400-24412 (2020).

66. Guo, B. et al. Contamination, Distribution and health riskassessment of risk elements in topsoil foramusement parks in Xi'an, China. Pol. J. Environ. Stud. 30, 601-617 (2021).

67. Hong, Y. et al. Comparing laboratory and airborne hyperspectral data for the estimation and mapping of topsoil organic carbon: Feature selection coupled with random forest. Soil Tillage Res. 199, 104589 (2020).

68. Kursa, M. B. \& Rudnicki, W. R. Feature selection with the Boruta package. J. Stat. Softw. 36, 1-13 (2010).

69. Rudnicki, W. R., Wrzesien, M. \& Paja, W. All relevant feature selection methods and applications. Comput. Intell.Us. 584, 11-28 (2015).

70. Liu, Z. et al. Estimation of soil heavy metals content using hyperspectral data. Remote Sens. Basel. 11, 1464 (2019).

71. Bellon-Maurel, V., Fernandez-Ahumada, E., Palagos, B. \& Roger, J. Critical review of chemometric indicators commonly used for assessing the quality of the prediction of soil attributes by Nir spectroscopy. Trac. Trend. Anal. Chem. 29, 1073-1081 (2010).

72. Wold, S., Martens, H. \& Wold, H. The multivariate calibration problem in chemistry solved by the PLS method. Lect. Notes Math. 973, 286-293 (1983).

73. Shi, T., Wang, J., Chen, Y. \& Wu, G. Improving the prediction of arsenic contents in agricultural soils by combining the reflectance spectroscopy of soils and rice plants. Int. J. Appl. Earth Obs. 52, 95-103 (2016).

74. Dotto, A. C., Dalmolin, R. S. D., Caten, A. T. \& Grunwald, S. A systematic study on the application of scatter-corrective and spectral-derivative preprocessing for multivariate prediction of soil organic carbon by Vis-Nir spectra. Geoderma 314, 262-274 (2018).

75. Breiman, L. Random forests. Mach. Learn. 45, 5-32 (2001).

76. Douglas, R. K. et al. Evaluation of Vis-Nir reflectance spectroscopy sensitivity to weathering for enhanced assessment of oil contaminated soils. Sci. Total Environ. 626, 1108-1120 (2018).

77. Guo, B. et al. Estimating socio-economic parameters via machine learning methods using Luojial-01 Nighttime Light remotely sensed images at multiple scales of China in 2018. IEEE Access. 9, 34352-34365 (2021).

78. Tan, K., Ma, W., Wu, F. \& Du, Q. Random forest-based estimation of heavy metals concentration in agricultural soils with hyperspectral sensor data. Environ. Monit. Assess. 191, 446 (2019).

79. Guo, B. et al. Estimating Pm2.5 concentrations via random forest method using satellite, auxiliary, and ground-level station dataset at multiple temporal scales across China in 2017. Sci. Total Environ. 778, 146288 (2021).

80. Ou, D. et al. Semi-supervised Dnn regression on airborne hyperspectral imagery for improved spatial soil properties prediction. Geoderma. 385, 114875 (2021).

81. Gholizadeh, A., Žižala, D., Saberioon, M. \& Borůvka, L. Soil organic carbon and texture retrieving and mapping using proximal, airborne and sentinel-2 spectral imaging. Remote Sens. Environ. 218, 89-103 (2018).

82. Guo, B. et al. Identifying the spatiotemporal dynamic of Pm 2.5 concentrations at multiple scales using geographically and temporally weighted regression model across China during 2015-2018. Sci. Total Environ. 751, 141765 (2021).

83. Guo, B. et al. Detecting spatiotemporal dynamic of regional electric consumption using Npp-Viirs Nighttime stable light data-a Case Study of Xi'an, China. IEEE Access 8, 171694-171702 (2020).

84. Guo, B. et al. A land use regression application into simulating spatial distribution characteristics of particulate matter (Pm2.5) concentration in city of Xi'an, China. Pol. J. Environ. Stud. 29, 4065-4076 (2020).

85. Malley, D. F. \& Williams, P. C. Use of near-infrared reflectance spectroscopy in prediction of heavy metals in freshwater sediment by their association with organic matter. Environ. Sci. Technol. 31, 3461-3467 (1997).

86. Pyo, J., Hong, S. M., Kwon, Y. S., Kim, M. S. \& Cho, K. H. Estimation of heavy metals using deep neural network with visible and infrared spectroscopy of soil. Sci. Total Environ. 741, 140162 (2020).

87. Sun, W. \& Zhang, X. Estimating soil zinc concentrations using reflectance spectroscopy. Int. J. Appl. Earth Obs. 58, 126-133 (2017). 
88. Chao, T. et al. A transferable spectroscopic diagnosis model for predicting arsenic contamination in soil. Sci. Total Environ. 669, 964-972 (2019).

89. Rossel, R. A. V., Walvoort, D. J. J., McBratney, A. B., Janik, L. J. \& Skjemstad, J. O. Visible, near infrared, mid infrared or combined diffuse reflectance spectroscopy for simultaneous assessment of various soil properties. Geoderma 131, 59-75 (2005).

90. Rossel, R. A. V. et al. A global spectral library to characterize the world's soil. Earth Sci. Rev. 155, 198-230 (2016).

91. Chakraborty, S. et al. Development of a hybrid proximal sensing method for rapid identification of petroleum contaminated soils. Sci. Total Environ. 514, 399-408 (2015).

92. Boker, A., Brownell, L. \& Donen, N. The Amsterdam preoperative anxiety and information scale provides a simple and reliable measure of preoperative anxiety. Can. J. Anesth. 49, 792-798 (2002).

93. Piñeiro, G., Perelman, S., Guerschman, J. P. \& Paruelo, J. M. How to evaluate models: Observed vs. predicted or predicted vs. observed?. Ecol. Model. 216, 316-322 (2008).

94. Douglas, R. K., Nawar, S., Alamar, M. C., Mouazen, A. M. \& Coulon, F. Rapid prediction of total petroleum hydrocarbons concentration in contaminated soil using Vis-Nir spectroscopy and regression techniques. Sci. Total Environ. 616, 147-155 (2018).

95. Ji, W., Rossel, R. A. V. \& Shi, Z. Accounting for the effects of water and the environment on proximally sensed Vis-Nir soil spectra and their calibrations. Eur. J. Soil Sci. 66, 555-565 (2015).

96. Altunkaynak, A. \& Ozger, M. Comparison of discrete and continuous wavelet-Multilayer perceptron methods for daily precipitation prediction. J. Hydrol. Eng. 21, 04016014 (2016).

97. Buddenbaum, H., Steffens, M. \& Rossel, R. V. The effects of spectral pretreatments on chemometric analyses of soil profiles using laboratory imaging spectroscopy. Appl. Environ. Soil Sci. 2012, 1-12 (2012).

98. Nawar, S., Buddenbaum, H., Hill, J., Kozak, J. \& Mouazen, A. M. Estimating the soil clay content and organic matter by means of different calibration methods of Vis-Nir diffuse reflectance spectroscopy. Soil Till. Res. 155, 510-522 (2016).

99. Kuang, B. \& Mouazen, A. M. Calibration of visible and near infrared spectroscopy for soil analysis at the field scale on three European farms. Eur. J. Soil Sci. 62, 629-636 (2011).

100. Sipos, P., Németh, T., Kis, V. K. \& Mohai, I. Association of individual soil mineral constituents and heavy metals as studied by sorption experiments and analytical electron microscopy analyses. J. Hazard. Mater. 168, 1512-1520 (2009).

101. Rossel, R. A. V. \& Behrens, T. Using data mining to model and interpret soil diffuse reflectance spectra. Geoderma 158, 46-54 (2010).

\section{Acknowledgements}

This work was supported by the Natural Science Foundation of Shaanxi Province (2021JM-388) and the Open Foundation of the State Key Laboratory of Urban and Regional Ecology of China (SKLURE2021-2-6). We are grateful to Master Candidate Wencai Zhang and Haojie Wu for checking and editing.

\section{Author contributions}

B.G.: Conceptualization, Methodology, Supervision. B.Z.: Writing Original draft preparation. Y.S.: Software. D.Z.: Investigation. H.B.: Validation. Y.W.: Editing. Y.B.: Data curation. L.S.: Visualization. X.G.: Visualization. All authors have read and approved the content of the manuscript.

\section{Competing interests}

The authors declare no competing interests.

\section{Additional information}

Supplementary Information The online version contains supplementary material available at https://doi.org/ 10.1038/s41598-021-99106-1.

Correspondence and requests for materials should be addressed to B.G.

Reprints and permissions information is available at www.nature.com/reprints.

Publisher's note Springer Nature remains neutral with regard to jurisdictional claims in published maps and institutional affiliations.

Open Access This article is licensed under a Creative Commons Attribution 4.0 International License, which permits use, sharing, adaptation, distribution and reproduction in any medium or format, as long as you give appropriate credit to the original author(s) and the source, provide a link to the Creative Commons licence, and indicate if changes were made. The images or other third party material in this article are included in the article's Creative Commons licence, unless indicated otherwise in a credit line to the material. If material is not included in the article's Creative Commons licence and your intended use is not permitted by statutory regulation or exceeds the permitted use, you will need to obtain permission directly from the copyright holder. To view a copy of this licence, visit http://creativecommons.org/licenses/by/4.0/.

(c) The Author(s) 2021 